\title{
Article \\ A Biofouling Resistant Zwitterionic Polysulfone Membrane Prepared by a Dual-Bath Procedure
}

\author{
Irish Valerie B. Maggay ${ }^{1}$, Hana Nur Aini ${ }^{1}$, Mary Madelaine G. Lagman ${ }^{2}$, Shuo-Hsi Tang ${ }^{1}$, Ruth R. Aquino ${ }^{2}$, \\ Yung Chang ${ }^{1, *}$ and Antoine Venault ${ }^{1, *}$ \\ 1 R\&D Center for Membrane Technology and Department of Chemical Engineering, \\ Chung Yuan Christian University, Chung-Li 32023, Taiwan; irish.maggay@gmail.com (I.V.B.M.); \\ hananuraini96@gmail.com (H.N.A.); steventang0321@cycu.org.tw (S.-H.T.) \\ 2 School of Chemical, Biological, and Materials Engineering and Science, Mapúa University, 658 Muralla St., \\ Intramuros, Manila 1002, Philippines; marymlagman@gmail.com (M.M.G.L.); \\ rraquino@mapua.edu.ph (R.R.A.) \\ * Correspondence: ychang@cycu.edu.tw (Y.C.); avenault@cycu.edu.tw (A.V.)
}

check for updates

Citation: Maggay, I.V.B.; Aini, H.N.; Lagman, M.M.G.; Tang, S.-H.; Aquino, R.R.; Chang, Y.; Venault, A A Biofouling Resistant Zwitterionic Polysulfone Membrane Prepared by a Dual-Bath Procedure. Membranes 2022, 12, 69. https://doi.org/ 10.3390/membranes12010069

Academic Editor: Ralph

Rolly Gonzales

Received: 18 December 2021

Accepted: 2 January 2022

Published: 4 January 2022

Publisher's Note: MDPI stays neutral with regard to jurisdictional claims in published maps and institutional affiliations.

Copyright: (c) 2022 by the authors. Licensee MDPI, Basel, Switzerland. This article is an open access article distributed under the terms and conditions of the Creative Commons Attribution (CC BY) license (https:// creativecommons.org/licenses/by/ $4.0 /)$.

\begin{abstract}
This study introduces a zwitterionic material to modify polysulfone (PSf) membranes formed by a dual bath procedure, in view of reducing their fouling propensity. The zwitterionic copolymer, derived from a random polymer of styrene and 4-vinylpyrridine and referred to as $\mathrm{zP}(\mathrm{S}-\mathrm{r}-4 \mathrm{VP})$, was incorporated to the PSf solution without any supplementary pore-forming additive to study the effect of the sole copolymer on membrane-structuring, chemical, and arising properties. XPS and mapping FT-IR provided evidence of the modification. Macrovoids appeared and then disappeared as the copolymer content increased in the range $1-4 \mathrm{wt} \%$. The copolymer has hydrophilic units and its addition increases the casting solution viscosity. Both effects play an opposite role on transfers, and so on the growth of macrovoids. Biofouling tests demonstrated the efficiency of the copolymer to mitigate biofouling with a reduction in bacterial and blood cell attachment by more than $85 \%$. Filtration tests revealed that the permeability increased by a twofold factor, the flux recovery ratio was augmented from $40 \%$ to $63 \%$ after water/BSA cycles, and irreversible fouling was reduced by $1 / 3$. Although improvements are needed, these zwitterionic PSf membranes could be used in biomedical applications where resistance to biofouling by cells is a requirement.
\end{abstract}

Keywords: polysulfone membrane; zwitterionic modification; antifouling membrane; blending

\section{Introduction}

Polysulfone (PSf) is one of the most commonly used materials in membrane technology [1]. Its chemical, thermal, and mechanical resistance, combined with its excellent hydrolytic stability and relatively inexpensive production costs, make it ideal for widespread use in membrane fabrication. It has been employed as the main membrane matrix material in a wide range of applications including: ultrafiltration for water treatment [2], gas separation [3], desalination via membrane distillation [4], hemodialysis [5], etc.

PSf membranes are commonly prepared by phase-inversion processes including wetimmersion [6-8], vapor-induced phase separation [4,9], or dry-wet phase inversion [10,11] because they are easily carried out, require relatively inexpensive equipment, and are reproducible and so are scalable.

However, the intrinsic hydrophobicity of polysulfone makes PSf membranes prone to fouling. In particular, biofouling can readily occur when the membranes come into contact with an aqueous environment. Thus, polysulfone membranes used in wastewater treatment, blood filtration, or any environment containing proteins, micro-organisms, or cells have to undergo a modification procedure in order to improve their water permeability and/or reduce their interactions with biofoulants [12]. 
Over 20 years ago, Whitesides' group presented some guidelines to prepare surfaces to resist the adsorption of proteins from liquids [13]. These procedures can be extended to the fabrication of anti-biofouling membranes. The formation of a protective hydration layer at the interface between the membrane and its surrounding environment is the key. This can be realized using a large variety of hydrophilic or amphiphilic materials incorporated into the membrane system via different surface or bulk modification techniques [14]. Some effective anti-biofouling materials are the PEGylated materials, derived from poly(ethylene glycol) (PEG) and the zwitterionic materials [15]. The latter are regarded as even more effective to efficiently trap water [16]. These materials can be included in membrane systems by coating (or physical adsorption) [17], grafting (or chemical adsorption) [18], or in-situ modification (also called the blending method) [19]. As mentioned above, PSf is a common material in membrane technology, thus the body of literature on the development of antifouling PSf membranes is quite important. Recently, Hou et al. blended a poly(ethyleneoxide)-grafted amphiphilic copolymer with PSf to develop renewable antibacterial and antifouling membranes [20]. In a study published this year, Zhong et al. investigated the preparation of hemodialysis membranes made of PEGylated PSf, and demonstrated the effect of PEG chains on the hydrophilicity and hemocompatibility of the membranes [21]. Yu et al. grafted a copolymer referred to as [3-(methacryloylamino)propyl]-dimethyl (3-sulfopropyl) ammonium hydroxide on the surface of PSf membranes to improve their resistance to bovine serum albumin fouling [22]. Yue et al. used poly(sulfobetaine methacrylate) (PSBMA) to modify PSf membranes via surface-initiated atom transfer radical polymerization in order to improve their blood compatibility, cytocompatibility, and biofouling resistance [23]. The same zwitterionic material, PSBMA, was used by Xiang et al. for the surface modification of PSf membranes to improve their antifouling properties [24]. They concluded that PSBMA associated with poly(sodium methacrylate) "showed a synergistic effect in the process of coagulation". In order to further maximize the grafting of SBMA on PSF membranes, Shahkaramipour et al. recently proposed to co-deposit the zwitterionic material with dopamine on the surface of PSf membranes [25].

Polymeric materials are not the only option to improve the antifouling properties of PSf membranes, and nanoparticles have also been proven to be a viable alternative to polymers [26-29], but the stability of these composite membranes can be questioned. Additionally, the vast majority of studies on the preparation of zwitterionic PSf membranes mention a surface modification process (grafting, coating). Very few studies, to our knowledge, have focused on the development of zwitterionic antifouling polysulfone membranes by an in-situ modification method. Yet this one-step membrane preparation and modification method is highly effective to readily prepare anti-biofouling porous membranes, as proven with poly(vinylidene fluoride)-based membranes [30]. The challenge of preparing zwitterionic copolymers compatible with hydrophobic membrane material needs to be tackled, in order to take advantage of both the exceptional properties of these materials and of the in-situ modification methods that allow fast membrane preparation, good stability, and easy scale-up.

In this study, we used a copolymer made of styrene and a 4-vinylpyridine unit that then underwent a zwitterionization reaction using iodomethane. Although never used so far in the design of PSf membranes, the zwitterionic copolymer can be solubilized with polysulfone. Thus, it is a potential effective material for reducing the fouling propensity of PSf membranes prepared by in-situ modification. The experiments carried out in the frame of this work aimed primarily at testing this hypothesis by preparing novel zwitterionic membranes by liquid-induced phase separation. Although we have extensively evaluated the biofouling properties of the zwitterion copolymer in our previous works, modifying PSf membranes by blending $\mathrm{zP}(\mathrm{S}-r-4 \mathrm{VP})$ indicates the versatility of the copolymer in terms of being able to be solubilized in various hydrophobic polymeric matrices. As a first objective (Figure 1), the effect of the sole copolymer on membrane structures was tentatively rationalized. Thus, no other additive was incorporated into the membrane 
system, unlike in many studies reporting the use of pore-forming agents to fabricate UF/MF PSf membranes [31-33]. Subsequently, the focus was shifted on the complete characterization of the membranes' physicochemical and wetting properties. At last, fouling was assessed using a large variety of biofoulants including proteins, bacteria, and whole blood. We hope to demonstrate that the zwitterionic derivative of poly(styrene-co-4vinylpyridine) has great potential as an antifouling material for polysulfone membranes prepared by phase inversion.

1

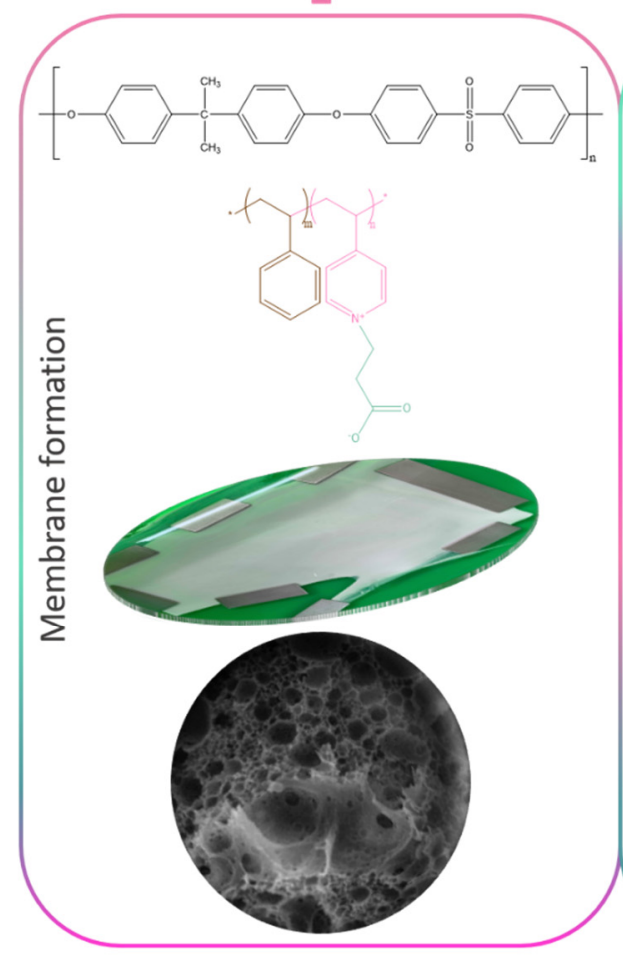

2

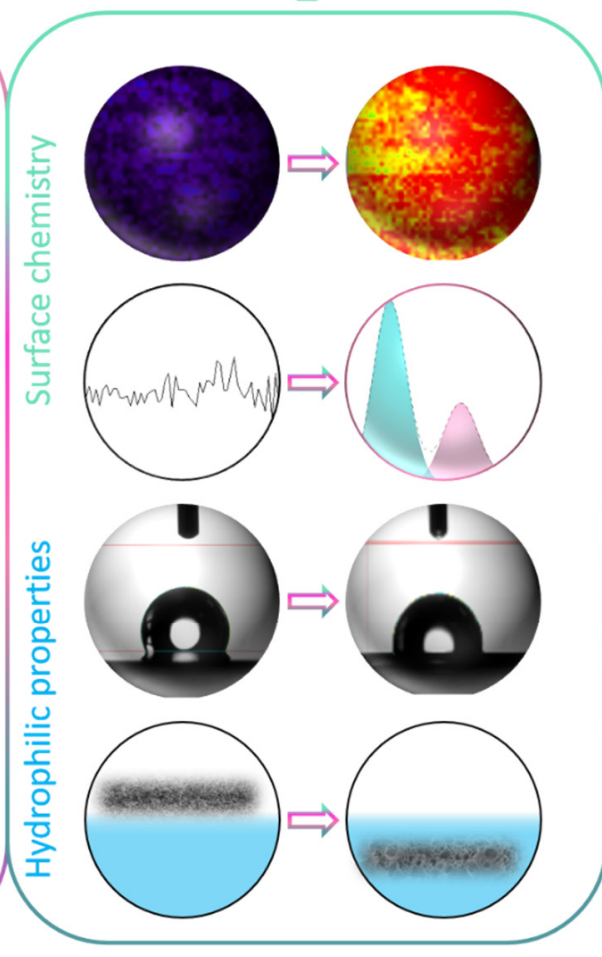

3

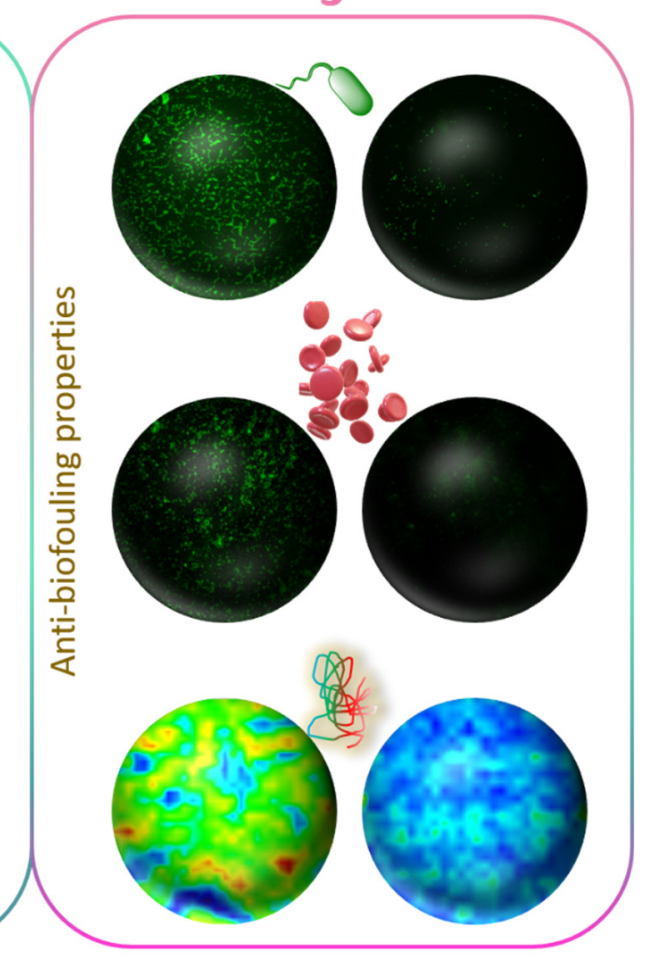

Figure 1. Schematic of the objectives of the work (1) to form zwitterionic polysulfone membranes by in-situ modification and rationalize membrane structure formation; (2) to characterize the changes in surface chemistry and surface/bulk hydration; (3) to evaluate the effect of the zwitterionic copolymer on biofouling using bacteria, blood cells, or proteins.

\section{Materials and Methods}

\subsection{Materials}

Styrene monomers and 4-vinlypyridine monomers with a purity greater than $99 \%$ and 95\%, respectively, were both purchased from Sigma-Aldrich, St. Louis, MO, USA. 2,2' Azobis(isoburyonitrile) (AIBN, $\geq 99.7 \%$ ) was bought from UniRegion Bio-Tech, Hsinchu, Taiwan. N,N-dimethylformamide ( $\geq 99.9 \%)(\mathrm{DMF})$ and N,N-dimethylacetamide ( $\geq 99.9 \%)$ (DMAC) were used as solvent for the copolymer synthesis and were purchased from Duksan Pure Chemicals Co., LTD, Ansan, South Korea. Acetone ( $\geq 99.9 \%)$ was also bought from Duksan Pure Chemicals Co., LTD, and used as a polarity modifier. Zwitterionization of the copolymer was performed using 3-iodopropionic acid (IPA, 99\%) obtained from Alfa Aesar, Massachusetts, USA. Methanol and toluene, both used as nonsolvents during the copolymer synthesis were purchased from Avantor Macron Fine Chemicals, Pennsylvania, USA. Amberlite ${ }^{\circledR}$ IRA-410 chloride form resin was obtained from Sigma-Aldrich and used to purify the copolymer by removing iodine.

The copolymer analysis involved the use of d-chloroform $(99.8 \mathrm{~atm} \% \mathrm{D})$ and tetrahydrofuran (inhibitor free) (THF) purchased from Sigma Aldrich and Tedia, Ohio, USA. respectively. Polysulfone, with an average molecular weight $\mathrm{Mw}$ of $50 \mathrm{kDa}$, was purchased from Amoco, and used as the matrix polymer for the membranes. Dimethylformamide, solvent for the casting solution preparation, was purchased from Duksan Pure Chemicals 
Co. LTD. Bovine serum albumin was bought from Merck. Whole blood was obtained from a pool of healthy volunteers at Mackay hospital (Taipei). DI-water was prepared in our laboratory with an Elga Purelab ${ }^{\circledR}$ system.

\subsection{Synthesis and Characterization of Random Copolymers}

The synthesis and characterization of copolymers has been presented earlier [34] and is briefly recalled here. Styrene and 4-vinylpyridine monomers were first mixed and dissolved in DMF solvent. The molar ratio of hydrophobic styrene to hydrophilic 4-vinylpyridine was fixed to $70 / 30$. In addition, the solid content was $30 \mathrm{wt} \%$. The initiator used for the reaction, $\mathrm{AIBN}$, was added to the homogeneous solution, controlling the monomer/initiator ratio to 1500 . Synthesis was conducted at $70{ }^{\circ} \mathrm{C}$ for $48 \mathrm{~h}$. Afterwards, the reaction was stopped by immersion of the reaction flask in ice for $30 \mathrm{~min}$. The newly formed copolymer, poly(styrene- $r$-4-vinylpyridine) or $\mathrm{P}(4-r-4 \mathrm{VP})$, was purified with water and methanol baths, and freeze-dried for 2 days.

The second part of the reaction consisted in synthesizing the zwitterionic copolymer, $\mathrm{zP}(4-r-4 \mathrm{VP})$, from the reaction of $\mathrm{P}(4-r-4 \mathrm{VP})$ with IPA. This reaction was performed in DMAC solvent. First, the copolymer obtained during the first part of the synthesis was dissolved in DMAC at $60{ }^{\circ} \mathrm{C}$ for $6 \mathrm{~h}$. Subsequently, IPA was added. The IPA/P(4- $\left.r-4 \mathrm{VP}\right)$ molar ratio was 1.2 , and the total solid content was controlled to $30 \mathrm{wt} \%$. After mixing the compounds for $24 \mathrm{~h}$, temperature was increased to $60^{\circ} \mathrm{C}$ to perform the reaction. After $24 \mathrm{~h}$, acetone was added to the reaction flask and stirring of the mixture was conducted for $10 \mathrm{~min}$. Subsequently, zP(4-r-4VP) was precipitated by dropwise addition of toluene. Finally, the copolymer was washed multiple times with acetone in an ultrasonic bath until the washing solution remained clear, and it was dried under vacuum for $24 \mathrm{~h}$, yielding a white material.

${ }^{1} \mathrm{H}$ NMR was used to verify the structure of $\mathrm{P}(4-\mathrm{r}-4 \mathrm{VP})$ copolymer and determine its exact styrene/4VP composition. XPS and FT-IR analyses were carried out to verify that the zwitterionization reaction was successful. ${ }^{1} \mathrm{H}$ NMR tests were conducted on a Bruker $600 \mathrm{MHz}$ instrument, using $\mathrm{CDCl}_{3}$ solvent, and a concentration of $25 \mathrm{mg} / \mathrm{mL}$. XPS analyses were run with a PHI Quantera instrument, equipped with an AI anode producing X-rays of photon energy $1486.6 \mathrm{eV}$. Spectra were fitted using Thermo Avantage software. FT-IR analyses of the copolymer were conducted with a Perkin Elmer Spectrum One spectrometer, in ATR mode. Spectral resolution was set to $4 \mathrm{~cm}^{-1}$. As the copolymer used in this study was introduced earlier, only some essential characterization results associated with the synthesized batch are briefly recalled in this section for convenience of the reader (Figure 2). Peaks on the ${ }^{1} \mathrm{H}$ NMR spectrum (Figure 2a) were assigned and those labelled $\mathrm{H}_{\mathrm{a}}$ (on pyridine groups) and $\mathrm{H}_{\mathrm{f}}$ (on styrene units) were used to determine the actual composition of the molar copolymer. It was found to be composed of $64 \%$ styrene (and so of $36 \%$ pyridine units). The molecular weight of the copolymer before zwitterionization was $108 \mathrm{kDa}$ (with an index of polydispersity of 1.9). It was measured with a Viscotec instrument using both LT4000L and LT3000L columns and THF as the mobile phase $(1 \mathrm{~mL} / \mathrm{min})$. XPS analysis also confirmed the successful zwitterionization reaction. While one peak only was logically found on the N1s core-level spectrum before reaction (at BE $399.4 \mathrm{eV}$ ), two peaks were identified on the spectrum after reaction (Figure $2 b$ ). The first small peak was also identified at about $399 \mathrm{eV}$, and corresponded to the pyridine groups, while the second larger peak was found at about $401.3 \mathrm{eV}$, and assigned to the pyridinium groups [35]. From these results, the degree of conversion of the pyridine group into pyridinium groups could be evaluated to be about 78\%. Finally, the FT-IR results confirmed the successful zwitterionization reaction, as the characteristic peak of the $\mathrm{C}=\mathrm{O}$ carbonyl functional group could be identified at $1725 \mathrm{~cm}^{-1}$, as well as that of the quaternized pyridine units at $1637 \mathrm{~cm}^{-1}$ (Figure 2c). 


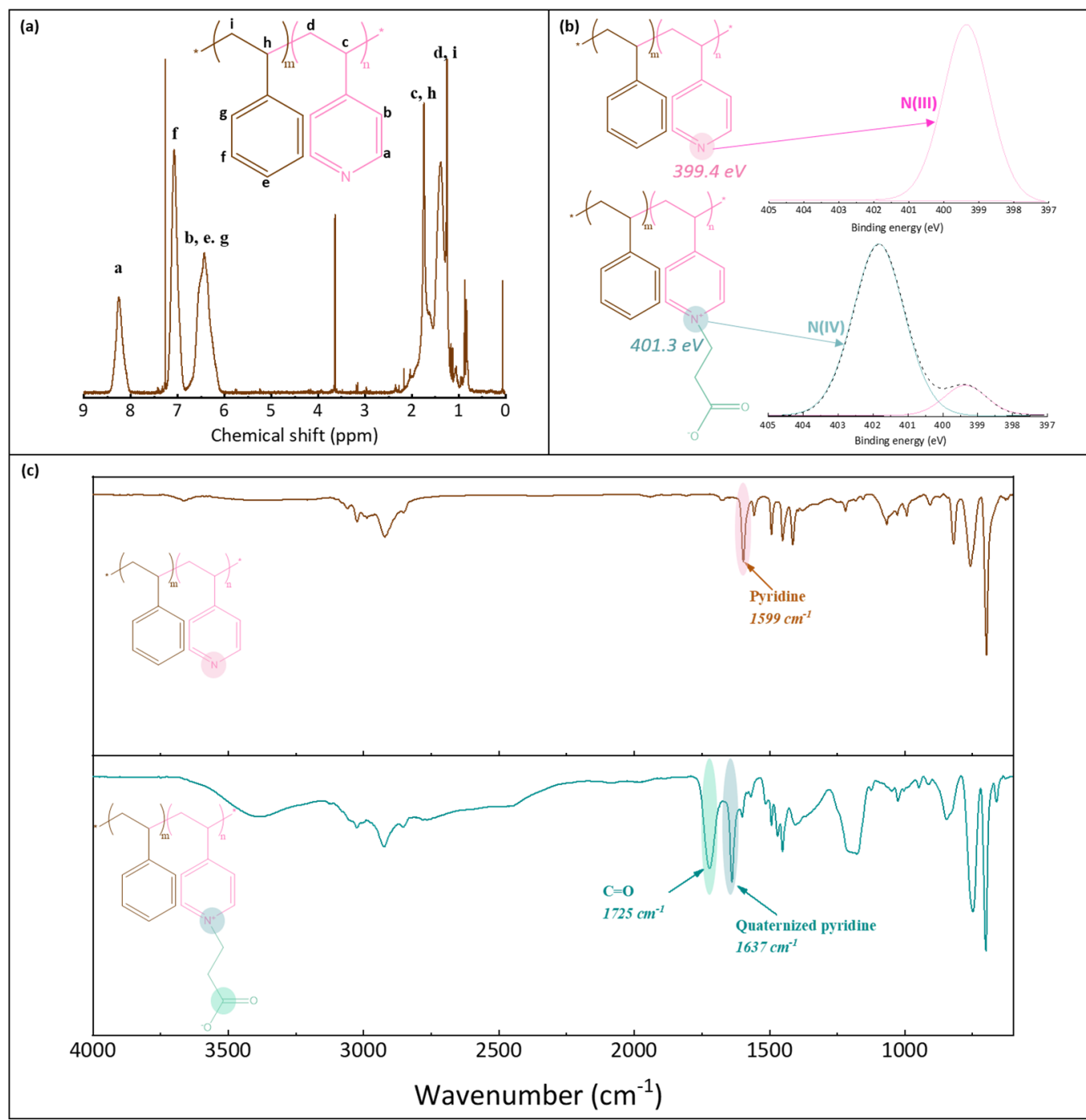

Figure 2. Characterization of poly(styrene- $r$-4-vinylpyridine) and zwitterionic poly(styrene- $r$-4vinylpyridine) copolymers. (a) ${ }^{1} \mathrm{H}$ NMR spectrum of $\mathrm{P}(\mathrm{S}-r-4 \mathrm{VP}),(\mathbf{b}) \mathrm{N} 1$ s core-level spectra of $\mathrm{P}(\mathrm{S}-r-4 \mathrm{VP})$ and $z \mathrm{P}(\mathrm{S}-r-4 \mathrm{VP})$, (c) FT-IR spectra of $\mathrm{P}(\mathrm{S}-r-4 \mathrm{VP})$ and $z \mathrm{P}(\mathrm{S}-r-4 \mathrm{VP})$.

\subsection{Casting Solution and Membrane Preparation}

Casting solutions were prepared by first dissolving the zwitterionic copolymer in DMF at $60{ }^{\circ} \mathrm{C}$. Subsequently, polysulfone was added to the solution and stirring continued at $60{ }^{\circ} \mathrm{C}$. Complete homogenization of the system was achieved after 2 days. The polysulfone content was fixed to $20 \mathrm{wt} \%$, while the zwitterionic copolymer content varied in the range $0-4 \mathrm{wt} \%$. Once the solution was homogeneous, stirring was stopped for several hours before casting, to permit the removal of bubbles of gas entrapped in the viscous solution.

The viscosity of the casting solution was determined with a Viscolite 700 portable viscometer. Measurements were almost instantaneous after immersion of the instrument probe in the casting solution.

Membranes were formed by wet-immersion using a dual-bath procedure. Solutions were cast on a glass substrate, with an initial thickness of $300 \mu \mathrm{m}$, and immersed for $10 \mathrm{~min}$ in methanol. Afterwards, they were transferred to a DI water bath to complete phase inversion. After $24 \mathrm{~h}$, membranes were washed with DI water to remove solvent traces, dried in air for $24 \mathrm{~h}$, and stored at $4{ }^{\circ} \mathrm{C}$ until use. 


\subsection{Light Transmittance Tests}

The change in light transmittance during phase inversion was monitored to highlight some potential effect of the zwitterionic copolymer on the kinetic of phase separation. Casting solutions of composition (PSf/zwitterionic copolymer/DMF: 20/4/76 wt $\%$ and $20 / 0 / 80 \mathrm{wt} \%$ ) were prepared as detailed above. These solutions were cast with a casting knife on a glass substrate permitting the initial thickness to be controlled to $300 \mu \mathrm{m}$. Metallic plates were positioned on each edge of the cast solution before immersion, to avoid detachment from the substrate during film formation which could cause disturbances in light transmittance measurement. Phase inversion was conducted in a container designed in such a way that its bottom comprises a transparent section. The glass substrate on which was cast the polymeric system was immersed in the bath and carefully positioned on the transparent section. A light collector (DLM 536, Tecpel Co., Taipei, Taiwan) was positioned below the forming film, and light transmittance continuously monitored throughout phase inversion. As phase separation occurred, light transmittance gradually decreased from $100 \%$ (corresponding to the initial transparent solution) to a plateau located at about $30 \%$ (corresponding to the final film).

\subsection{Physical Characterization of Membranes}

Membranes were observed with a Hitachi scanning electron microscope (SEM) S-3000. Prior to observation, membrane samples were positioned on a SEM holder, and sputtercoated with gold. For the observations of cross-sections, the samples were fractured using liquid nitrogen. The accelerating voltage was set to $15 \mathrm{eV}$.

Porosity was determined by gravimetric measurement using butanol, a solvent that neither swells the membrane nor solubilizes the polymers. First, dry samples (of diameter $1 \mathrm{~cm}$ ) were weighed $\left(W_{D}\right)$. Subsequently, samples were immersed in the alcohol bath for $24 \mathrm{~h}$. Wet samples were then weighed after gently wiping off butanol droplets from the surface of the membranes with some tissue cloth $\left(W_{W}\right)$. Knowing the density of butanol $\left(\rho_{b}\right)$, and of the polymer or of the mixture of polymers $\left(\rho_{p}\right)$, the porosity $(\varepsilon, \%)$ could then be determined from the following equation:

$$
\varepsilon(\%)=\frac{\frac{W_{w}-W_{d}}{\rho_{b}}}{\frac{W_{w}-W_{d}}{\rho_{b}}+\frac{W_{d}}{\rho_{p}}} \times 100
$$

Note that for membranes containing both polysulfone and $\mathrm{zP}(\mathrm{S}-r-4 \mathrm{VP})$, the density of the copolymer needed to be determined to assess the density of the polymer mixture. It was evaluated from the knowledge of the composition of the copolymer and from the molecular weight and density of each type of unit forming the copolymer. Tests were repeated 5 times.

When possible, the surface pore size was evaluated from SEM images using Image ${ }^{\circledR}$ software. Otherwise, the membrane pore size was calculated using the Guerout-ElfordFerry equation as follows:

$$
r_{m}=\sqrt{\frac{(2.9-1.75 \varepsilon) \times 8 \eta l Q}{\varepsilon \times A \times \Delta P}}
$$

where $\varepsilon$ is the porosity found from Equation (1), $\eta$ is the viscosity of water at the temperature of the test (taken as $\left.0.89 \times 10^{-3} \mathrm{~Pa} \cdot \mathrm{s}\right), l(\mathrm{~m})$ is the thickness of the membrane evaluated from the SEM image of the cross-section, $Q\left(\mathrm{~m}^{3} / \mathrm{s}\right.$ ) is the volumetric flow rate (amount of permeate collected per unit of time), $A$ is the membrane surface area $\left(\mathrm{m}^{2}\right)$, and $\Delta P(\mathrm{~Pa})$ the transmembrane pressure.

\subsection{Chemical Characterization of Membranes}

The surface chemistry of membranes was characterized by XPS, ATR-FTIR, and mapping FT-IR. The XPS instrument was the same as that used to characterize the copolymer 
(Section 2.2). However, both the C1s and N1s core-level spectra were analyzed for the membrane systems. The FT-IR analysis was conducted with a Jasco system combining a spectroscope for ATR analyses and a microscope for mapping analyses (FT-IR 6700 and IRT-5200). Samples were first dried. ATR-FTIR analyses were run at a resolution of $4 \mathrm{~cm}^{-1}$. Maps were acquired over a surface of $4 \mathrm{~mm}^{2}$ at a wavelength centered at $1727 \mathrm{~cm}^{-1}$ (corresponding to the $\mathrm{C}=\mathrm{O}$ function of the carboxylate group of the zwitterionic copolymer) and setting the aperture to $100 \mu \mathrm{m}$. At each point of the map, a spectrum was obtained by averaging 32 scans (with a resolution of $4 \mathrm{~cm}^{-1}$ ). The background for the analyses was a gold surface. Each map is color-coded. If there is no functional group, the map will be dark blue, while if there is a high density of functional groups, it will be red.

\subsection{Characterization of Membranes' Hydrophilic Properties}

The membranes' hydrophilic properties were determined by measuring their water contact angle (WCA) and their hydration capacity in water. For WCA tests, a DataPhysics OCA15EC instrument was used. A water droplet of a volume of about $4 \mu \mathrm{L}$ was automatically dropped on dried samples positioned on a glass slide place on the stage of the angle meter. Subsequently, snapshots were taken and the WCA automatically measured. In this work, WCA is reported at $3 \mathrm{~s}$. Ten independent tests were performed, and data reported as mean $\pm \mathrm{SD}$. Hydration capacity was measured by immersing dry samples (of diameter $13 \mathrm{~mm}$ ) in DI water for $24 \mathrm{~h}$. The hydration capacity corresponds to the difference per unit surface area between the wet weight of the samples (after immersion) and the dry weight (before immersion). It will be expressed in $\mathrm{mg} / \mathrm{cm}^{2}$ and results of 5 independent tests are reported as mean $\pm \mathrm{SD}$.

\subsection{Biofouling Tests}

A number of fouling tests were performed to assess the efficiency of zP(S-r-4VP) to provide polysulfone membranes with biofouling resistance. Adsorption tests were carried out using Escherichia coli (E. coli) modified with a green fluorescent protein, whole blood, or bovine serum albumin (BSA). Filtration tests were carried out using BSA.

E. coli attachment tests were performed by incubating $1 \mathrm{~mL}$ of bacterial solution (whose preparation was detailed by Hsiao et al. [36]) with samples of diameter $13 \mathrm{~mm}$, in a 24-well microplate. Prior to the incubation, samples were incubated with PBS overnight. Incubation of the bacterial solution with the polysulfone-based membranes was conducted for $24 \mathrm{~h}$ in a chamber in which the temperature was set to $37^{\circ} \mathrm{C}$. The bacterial solution was changed 3 times over the incubation period, at $t=6 \mathrm{~h}, 12 \mathrm{~h}$, and $18 \mathrm{~h}$, to guarantee that live microorganisms would constantly be in contact with the membrane samples. Subsequently, membranes were rinsed with PBS, and observed with a Nikon A1R confocal microscope. Three independent samples were used for each condition of membrane preparation, and 3 images analyzed for each sample. Hence the quantitative data obtained using Image ${ }^{\circledR}$ software correspond to an average of 9 analyses, and are reported as mean $\pm \mathrm{SD}$.

Whole blood attachment tests were conducted with blood obtained from healthy individuals. Samples of $13 \mathrm{~mm}$ were positioned in well plates, and washed with PBS at $37^{\circ} \mathrm{C}$ overnight. Subsequently, PBS was replaced with $0.8 \mathrm{~mL}$ of whole blood. After $4 \mathrm{~h}$ at $37^{\circ} \mathrm{C}$ in the incubation chamber, membranes were washed with PBS, and fixed with a solution of glutaraldehyde at $4{ }^{\circ} \mathrm{C}$ for $4 \mathrm{~h}$, before observation with a Nikon A1R confocal microscope. As in the bacterial attachment tests, the analysis of images was carried out with Image ${ }^{\circledR}$ in a similar way (number of samples, images, etc.) to obtain an average (reported as mean $\pm \mathrm{SD}$ ) surface coverage of membranes by whole blood cells.

BSA adsorption tests were carried out as follows. First, dry membranes were incubated with a solution of BSA $(1 \mathrm{~g} / \mathrm{L})$ for $2 \mathrm{~h}$. Subsequently, membranes were scanned by mapping FT-IR using the same instrument mentioned in Section 2.6. Maps were obtained at $1650 \mathrm{~cm}^{-1}$, and compared to maps of membranes before incubation with the protein solution. 
Filtration tests with BSA were performed in a dead-end filtration cell using circular membrane samples having a diameter of $26 \mathrm{~mm}$. Samples were integrated with a nonwoven support into a stirring cell. DI water was first filtered at 3.5 bar and $1100 \mathrm{rpm}$ until reaching steady-state flow. Subsequently, the pressure was decreased to 3 bar, the cell loaded with $50 \mathrm{~mL}$ of DI water, and water flux recorded for about $30 \mathrm{~min}$. Secondly, the cell was filled with $50 \mathrm{~mL}$ of a solution of BSA (in PBS) of concentration $1 \mathrm{~g} / \mathrm{L}$, and the flux continuously recorded until the emptying of the cell. Subsequently, the membrane was washed by immersion in DI water followed by a backflushing step using DI water and lasting $10 \mathrm{~min}$. Subsequently, all operations (filtration with $50 \mathrm{~mL}$ of DI water, $50 \mathrm{~mL}$ of BSA, washing) were carried out a second time, followed by a last filtration step with pure DI water. From the knowledge of the initial water flux $\left(J_{w, i}\right)$, the final protein solution flux $\left(J_{B S A, f}\right)$ as recorded during the second cycle, and the final water flux as recorded at the end of the test $\left(J_{w, f}\right)$, it was possible to determine essential ratios associated with fouling. These were the flux recovery ratio $(F R R)$, the reversible flux decline ratio $\left(D R_{r}\right)$, the irreversible flux decline ratio $\left(D R_{i r}\right)$, and the total flux decline ratio $\left(D R_{t}\right)$. Their definitions are as follows:

$$
\begin{gathered}
F R R=\frac{J_{w, f}}{J_{w, i}} \times 100 \\
D R_{r}=\frac{J_{w, f}-J_{B S A, f}}{J_{w, i}} \times 100 \\
D R_{i r}=\frac{J_{w, i}-J_{w, f}}{J_{w, i}} \times 100 \\
D R_{t}=D R_{r}+D R_{i r}
\end{gathered}
$$

\section{Results and Discussion}

\subsection{Physical Properties of Membranes}

Membranes were hand-cast on glass plates, and the final dimensions of each membrane were at least $15 \mathrm{~cm} \times 20 \mathrm{~cm}$ (Figure 3a). Membranes appeared whitish with a matte appearance (as opposed to shiny). Several membrane sheets were prepared for each formulation condition, from which samples were taken for further characterization.

From the matte appearance of membrane surfaces after preparation, one could conclude that porous membranes were obtained which would then be confirmed by SEM. Small pores could be seen on the membranes' surface, although the pore size and surface porosity decreased with the copolymer content.

Wet-immersion with DI water as the sole non-solvent, using DMF solvent for the polymer and a similar polysulfone concentration (20 wt $\%$ ) led to the formation of a dense, thick skin layer (Figure 4) with a porous sublayer. The presence of this skin layer can be attributed to the gelation that has occurred as a result of the increased polymer concentration at the top layer during wet-immersion [37]. The high affinity of DMF towards water caused it to be abruptly exhausted as soon as the polymeric solution came in contact with the non-solvent (water) [38]. On the other hand, the presence of a more porous surface (P20-Z0) is likely due to the lower non-solvent power of methanol. The coarsening of the domains at the top surface observed with water as the sole non-solvent, and commonly leading to the formation of a dense skin, was partially prevented with methanol. Immersion in this weaker non-solvent enabled the retainment of the porous interface. The apparent decrease in surface pore size (as seen on the SEM image) with the addition of a copolymer can be explained by the increase in total polymer content, and so by the decrease in the free volume in the polymeric membrane. Meanwhile, cross-sectional images evidenced the presence of large pores, some similar to macrovoids in the bulk of P20-Z1, P20-Z2, and P20-Z3 membranes. They were absent from the cross-section of P20-Z0, and although large pores could still be seen in the cross-section of P20-Z4, these were not typical macrovoids. The appearance of macrovoids followed by their disappearance as the copolymer content increases can be rationalized as follows. First, the hydrophilic units of the zwitterionic 
copolymer tend to accelerate the penetration of non-solvent in the polymeric system during phase-inversion, as seen from the results of light transmittance tests (Figure 5a). However, adding copolymer into the casting solutions (which all contained a fixed polysulfone content) also increases the viscosity of the casting solution (Figure $5 b$ ). The latter slows down mass transfers. The presence of macrovoids is often associated with fast water penetration during film formation although some inconsistencies were pointed out in the paper of Hung et al. who stressed the need for more investigations to unify the theories on the formation of these structures [39]. Fast exchanges promote macrovoid formation. However, the use of a weak non-solvent (methanol) slowed exchanges and the formation of fingers. While phase separation and domain growth were still initiated in the first bath, these domains offered a resistance to water diffusion during immersion in the second bath. At low copolymer content (1-3 wt \%), the zwitterionic units, hydrophilic, accelerated non-solvent transfers during the second immersion, and macrovoids were then observed. However, fast mass transfers were offset by the rise in viscosity in the case of P20-Z4, which would explain the disappearance of the macrovoids in this membrane. Moreover, it is noticeable in Figure $5 b$ that the viscosity drastically increased above a certain polymer concentration which could be attributed to the entanglement of polymer chains. This phenomenon is said to occur when the amount of polymer reaches a specific threshold [39]. To determine this, the changes in the slopes of the different polymer concentrations are taken into consideration, and the intersection of these slopes can be interpreted as the threshold concentration, denoted as entanglement concentration $\left(C_{e}\right)$ (Figure $5 \mathrm{~b}$ inset). From this, we determined that $C_{e}=22.36 \mathrm{wt} \%$. Hung et al. suggested that when the polymer concentration in the casting solution is above the $C_{e}$ and polymer chains are entangled, the starting positions (initiations) of the macrovoid growth are found below the membrane surface. Hence, in the SEM cross-section image of P20-Z3, the macrovoid growth started at the deeper part of the membrane, while in P20-Z4, the macrovoids completely disappeared, as these concentrations are above the $C_{e}$. Aside from viscosity, another rheological factor that needs to be considered is the viscoelasticity of the casting solution which will be taken into account in future work in this study.

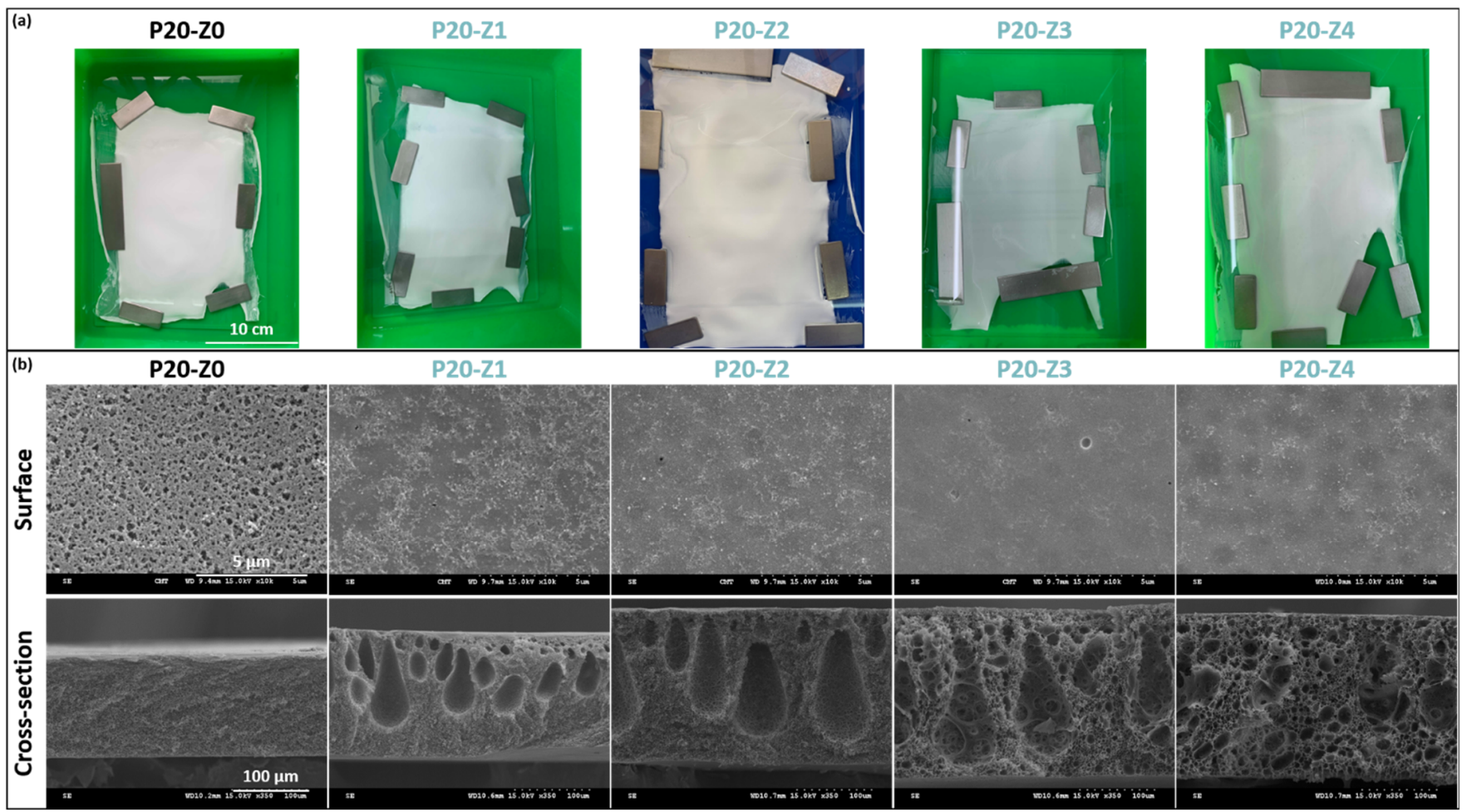

Figure 3. Physical characterization of membranes' structure. (a) Photographs of virgin and zwitterionic membranes; (b) SEM analysis of surface and cross-section of virgin and zwitterionic membranes. 

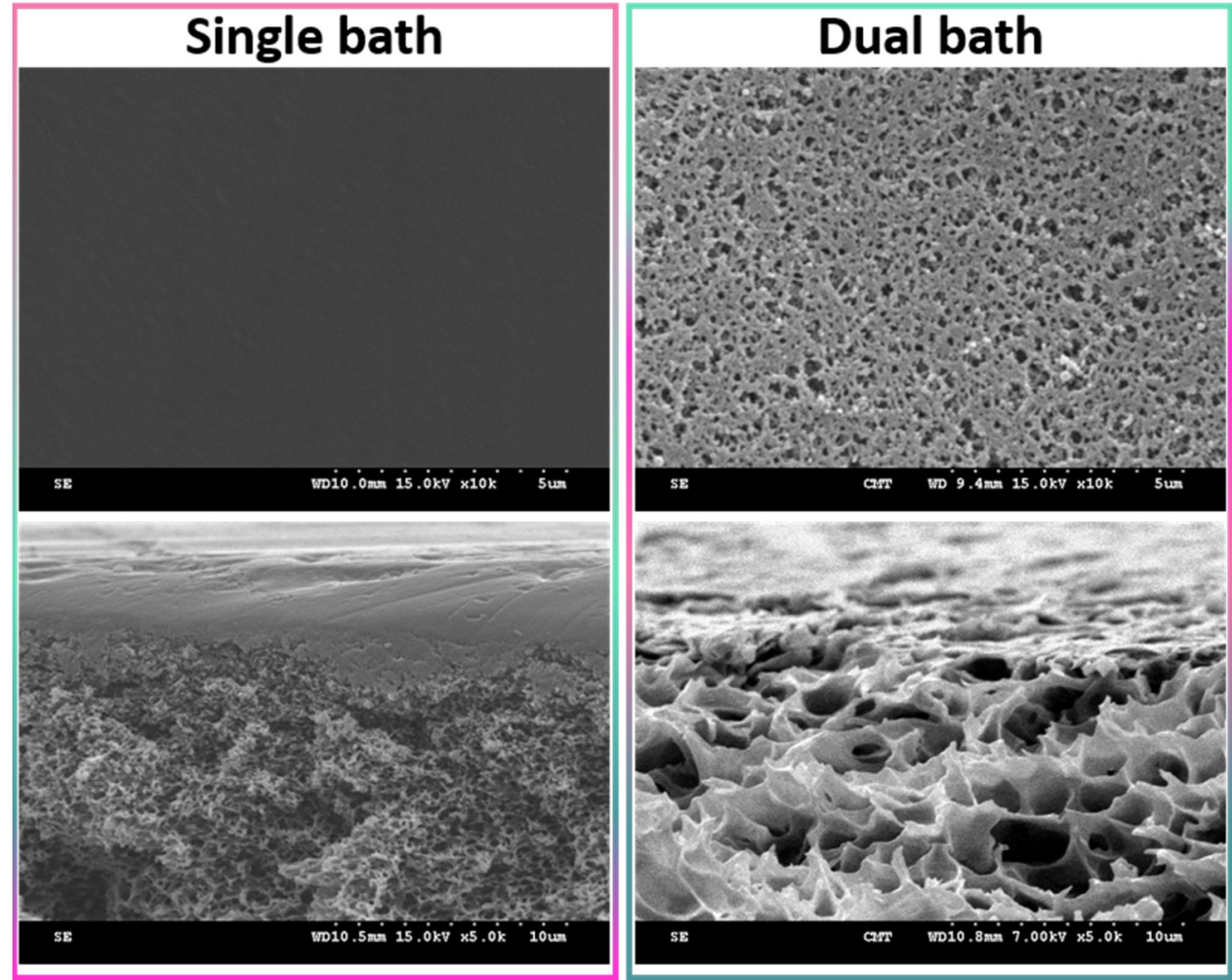

Figure 4. Surface of a polysulfone membrane prepared using DMF as solvent and either water as the sole non-solvent (single bath procedure) or both methanol and water as non-solvents (dual bath procedure). Top images present the surface, while the bottom images show the cross-section in the upper region.
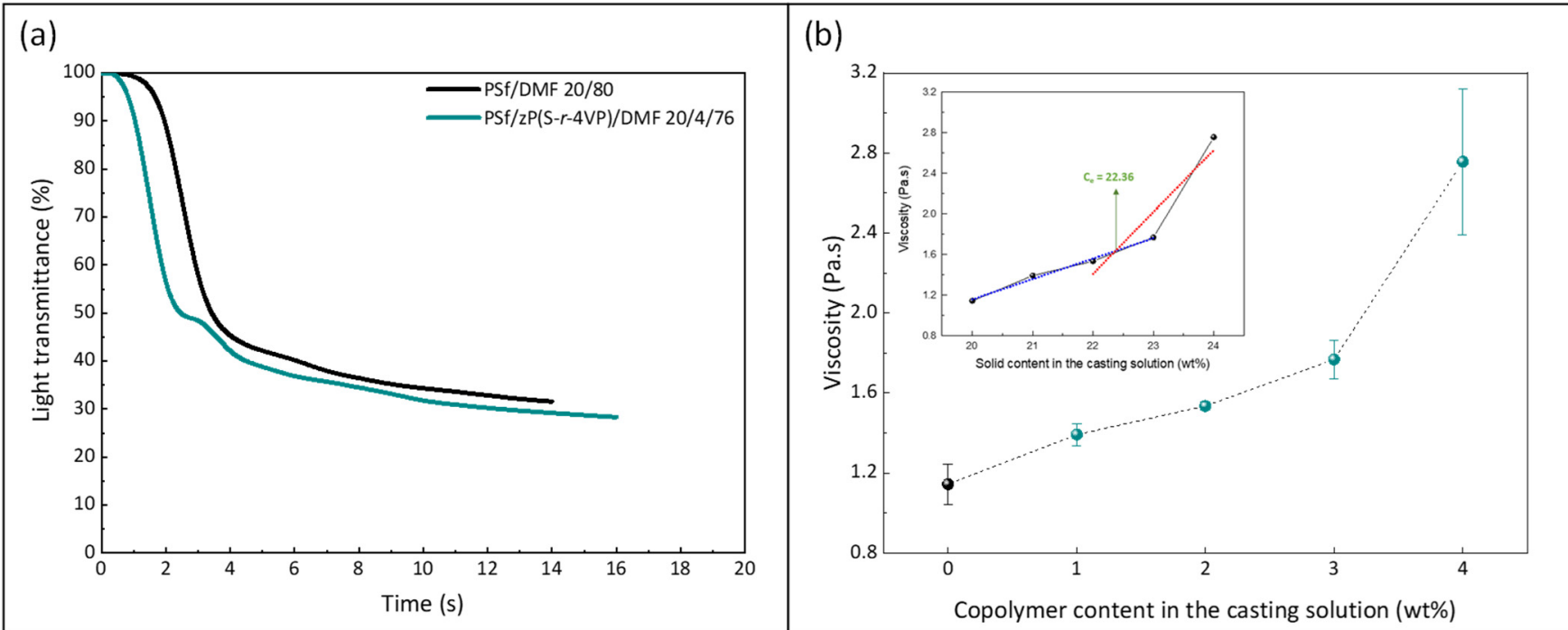

Figure 5. Effect of the copolymer on (a) kinetic of phase separation and (b) viscosity of the casting solution ( $0 \mathrm{wt} \%$ corresponds to the casting solution used to form the virgin membrane P20-Z0). Measurements performed at $25{ }^{\circ} \mathrm{C}$. (Inset: determined chain entanglement concentration of the PSf/copolymer/DMF system).

The pore size and porosity are presented in Table 1 . The measured porosity, ranging between $73 \%$ and $81 \%$, is consistent with the presence of macrovoids and large pores decorating the bulk of the membranes. The addition of amphiphilic zP(S-r-4VP) tends to slightly increase the matrix porosity. This effect of amphiphilic copolymers has been 
reported earlier $[40,41]$. The surface pore size could be measured from SEM images for the P20-Z0 membrane and was found to be quite large. Nevertheless, for the modified membranes, large surface pores were difficult to detect in large quantity. Thus, only the membrane pores were evaluated for these membranes using Equation (2). It is interesting to note that for P20-Z0, the membrane pores are much smaller than the surface pores, making the membrane fall in the lower region of the UF range. Modified membranes also present nanometer-scale pores, slightly larger than those of the modified membranes. Hence, although larger surface pores are hardly detected on the zwitterionic membranes, unlike the virgin membrane, they have larger bulk pores which benefit the membrane permeability.

Table 1. Porosity and pore size of the virgin and modified PSf membranes. ${ }^{(1)}$ Evaluated when possible from SEM, (2) Evaluated from Equation (2).

\begin{tabular}{cccc}
\hline Membrane ID & Porosity (\%) & Surface Pore Size $(\mu \mathbf{m}){ }^{(\mathbf{1})}$ & Mean Pore Size (nm) ${ }^{(2)}$ \\
\hline P20-Z0 & $73.2 \pm 1.4$ & $0.9 \pm 0.3$ & 6.3 \\
\hline P20-Z1 & $77.0 \pm 1.5$ & $/$ & 9.1 \\
\hline P20-Z2 & $80.2 \pm 0.5$ & $/$ & 10.4 \\
\hline P20-Z3 & $79.2 \pm 0.5$ & $/$ & 10.3 \\
\hline P20-Z4 & $74.1 \pm 1.5$ & $/$ & 10.4 \\
\hline
\end{tabular}

\subsection{Chemical Properties of Membranes}

The chemical composition of the membranes' surfaces was characterized by FT-IR and XPS spectroscopy and results related to P20-Z0 (virgin) and P20-Z4 (modified) membranes, as shown in Figure 6. Although weak, the characteristic signal of $\mathrm{C}=\mathrm{O}$ belonging to the carboxylate functional group of the copolymer can be detected at about $1727 \mathrm{~cm}^{-1}$ (Figure 6a). Thus, FT-IR can detect the presence of the copolymer on the surface of the modified membranes. Nevertheless, the XPS analysis was more helpful to evidence directly the pyridinium groups. The N1s core-level spectrum of P20-Z4 shown in Figure 7 reveals two peaks, one centered at $\mathrm{BE} 402.1 \mathrm{eV}$, corresponding to the pyridinium salt, and another one at BE $399.3 \mathrm{eV}$ associated with the pyridine groups (which did not react with iodopropionic acid during the zwitterionization reaction) [34]. Logically, there is no signal seen on the N1s core level spectrum of the virgin membrane. Besides this, the analysis of the $\mathrm{C} 1 \mathrm{~s}$ core-level spectra reveals significant differences between the surface of the two membranes. Peaks of polysulfone membrane could be assigned with the help of the literature $[42,43]$. Subsequently, deconvolution analysis of the spectrum of P20-Z4 exposes two supplementary peaks, compared to the spectrum of P20-Z0, centered at BE $284.9 \mathrm{eV}$ and $290.3 \mathrm{eV}$, corresponding to $[\mathrm{C}=\mathrm{N}]$ and $[\mathrm{O}-\mathrm{C}=\mathrm{O}]$ species brought by $\mathrm{zP}(4-\mathrm{r}-4 \mathrm{VP})$, respectively. Finally, a peak centered at $\mathrm{BE} 533.8 \mathrm{eV}$ and corresponding to $[\mathrm{O}=\mathrm{C}]$ species can be seen on the O1s core-level spectrum of P20-Z4, associated with the carboxylate group of the zwitterionic copolymer. In addition, the elemental compositions of P20-Z0 and P20-Z4 are also illustrated. According to the XPS analysis, the surface of P20-Z4 has $2.37 \%$ nitrogen content (corresponding to the quaternized pyridine). Theoretically, we should obtain about $4 \%$; however, it is worth noting that XPS only has a detection depth of $5 \mathrm{~nm}$. Since blending entails bulk modification, some of the copolymers could be trapped inside the bulk of the PSf membranes. 


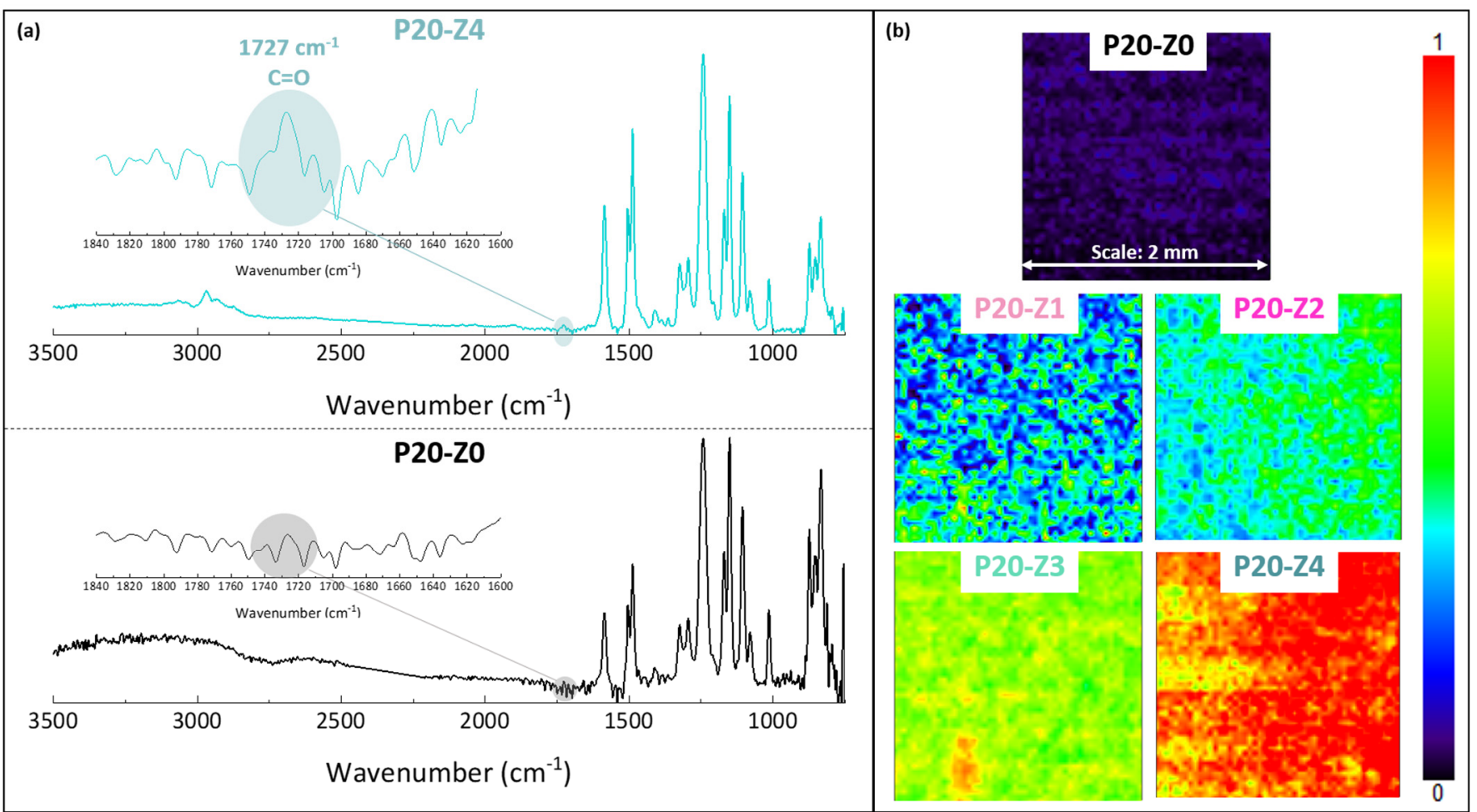

Figure 6. Chemical characterization of membranes by FT-IR (a) ATR-FTIR characteristic spectra of virgin (P20-Z0) and zwitterionic (P20-Z4) membranes. (b) Mapping FT-IR analysis of the different membranes, performed at $1727 \mathrm{~cm}^{-1}(\mathrm{C}=\mathrm{O})$.

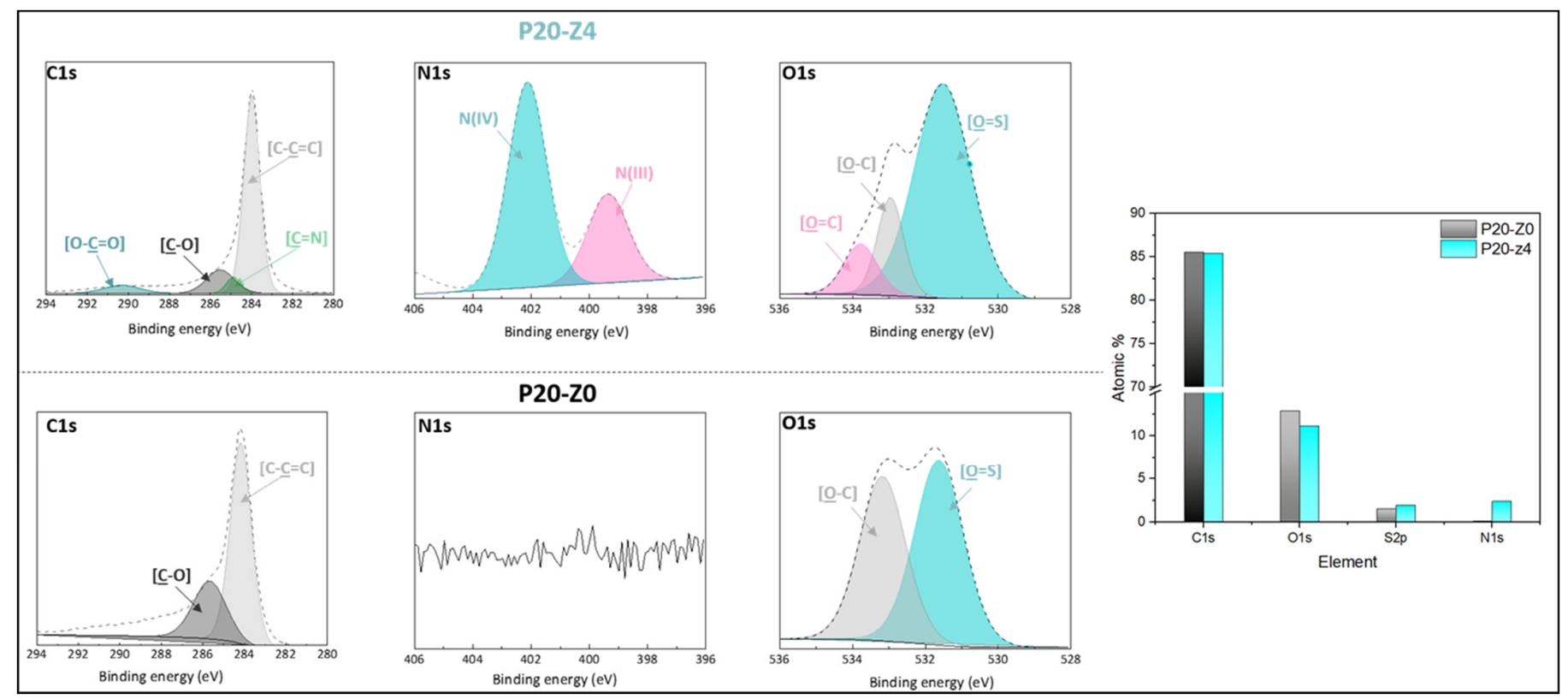

Figure 7. C1s, N1s, and O1s core-level spectra of P20-Z0 and P20-Z4 membranes and their corresponding elemental compositions.

A FT-IR mapping analysis of the membranes' surfaces was also performed, to assess the level of homogeneity of the surface modification. Maps of the surfaces presented in Figure $6 \mathrm{~b}$ are color-coded. A dark blue color signifies that the functional group of interest cannot be found while red color on the other end of the color scale means that the copolymer is present at a high density. Surfaces were mapped at $1727 \mathrm{~cm}^{-1}$, corresponding to the $\mathrm{C}=\mathrm{O}$ functional group of the copolymer. Thus, the map corresponding to P20-Z0 (virgin 
membrane) is logically dark blue as this membrane does not contain any copolymer. As the copolymer content in the casting solution increased, the maps of the resulting membrane became light blue and green (P20-Z1), green with blue spots (P20-Z2), green with yellow areas (P20-Z3) and red with orange/yellow spots (P20-Z4). This change in color is logical as it supports the increasing surface density of the copolymer with its initial concentration in the casting solution. Nevertheless, it is important to note that these maps (except maybe that of P20-Z1) are constituted by one major color, or by two adjacent colors on the scale, which implies that the surfaces have reached some level of homogeneity at a large scale (scale bar is $2 \mathrm{~mm}$ ), and so that the membrane preparation process is fairly well controlled.

All in all, these chemical analyses confirm the presence of the copolymer on the surface of the modified membranes. Therefore, changes should be detected concerning the wetting behavior and more importantly, the resistance to biofouling.

\subsection{Hydrophilic Properties of Membranes}

Hydrophilicity is regarded as one important key to the nonfouling behavior of a surface $[13,44]$. While superhydrophobicity can keep a membrane clean (i.e., free of dust, bacteria, proteins, etc.) when stored in air, it is not sustainable when the membrane is applied to a separation process involving some aqueous medium (as in many applications of porous membranes) because membrane wetting must occur. Thus, superhydrophobic porous membranes are ideal for a handful of applications where selective wettability (e.g., oil/water separation from oil-rich emulsion separation) is needed, but cannot really be employed for the filtration of wastewater or biological fluids. For these applications, wetting by water must occur. To protect the membrane from fouling in these environments, the membrane material should exhibit an improved affinity for water. This is because water molecules have to be expelled from the membrane material and from the biofoulant surface (e.g., protein) to reduce the free energy and make biofouling possible in aqueous media. While no (or little) control can be achieved over the hydration of the biofoulant, a proper surface or bulk modification can help strengthen the hydration layer of a membrane, and so reduce its propensity to foul.

Here, we chose to modify the polysulfone membrane with a zwitterionic copolymer via in-situ modification. Although surface segregation occurs during the phase inversion of such membranes prepared by blending a hydrophobic polymer with a more amphiphilic copolymer [45], not all molecules of the copolymer can be found at the surface. Thus, compared to a surface modification process (grafting, coating), the surface properties, including the water contact angle (WCA) in air, cannot be importantly modified. It is seen here in Figure 8 that the WCA in air of the modified membranes was about $100^{\circ}$, while it was $120^{\circ}$ for the virgin membrane. While this does show some improvement of the hydrophilicity of the surface, this is certainly not low enough to prevent fouling of the membrane surface in water. However, when the membrane is used in separation, it is usually immersed for some time in the aqueous environment. Wetting may take time but does occur when the amphiphilic material has been blended with the hydrophobic polymer. The WCA in air was measured a few seconds after dropping water on the surface of the membrane, and so it does not represent the actual affinity of the modified membranes with water when contacted with the liquid environment for a time long enough to establish hydrophilic interactions. Hydration capacity (HC) measurements, however, involve a 24-h immersion of the membrane material with DI water. The results of Figure 8 show an important increase in $\mathrm{HC}$ when comparing the virgin membrane to the modified ones. While it was measured to be about $50 \mathrm{mg} / \mathrm{cm}^{3}$ for the virgin membrane, it almost reached $275 \mathrm{mg} / \mathrm{cm}^{3}$ for P20-Z4 membrane. This result proves that water molecules can be more easily trapped in the bulk of the modified membrane, physically (in the pore) or chemically (interactions with the zwitterionic heads), because of the modification of the casting solution with the amphiphilic copolymer. Hence, the modified membranes should be less prone to fouling than the virgin PSf membrane. 


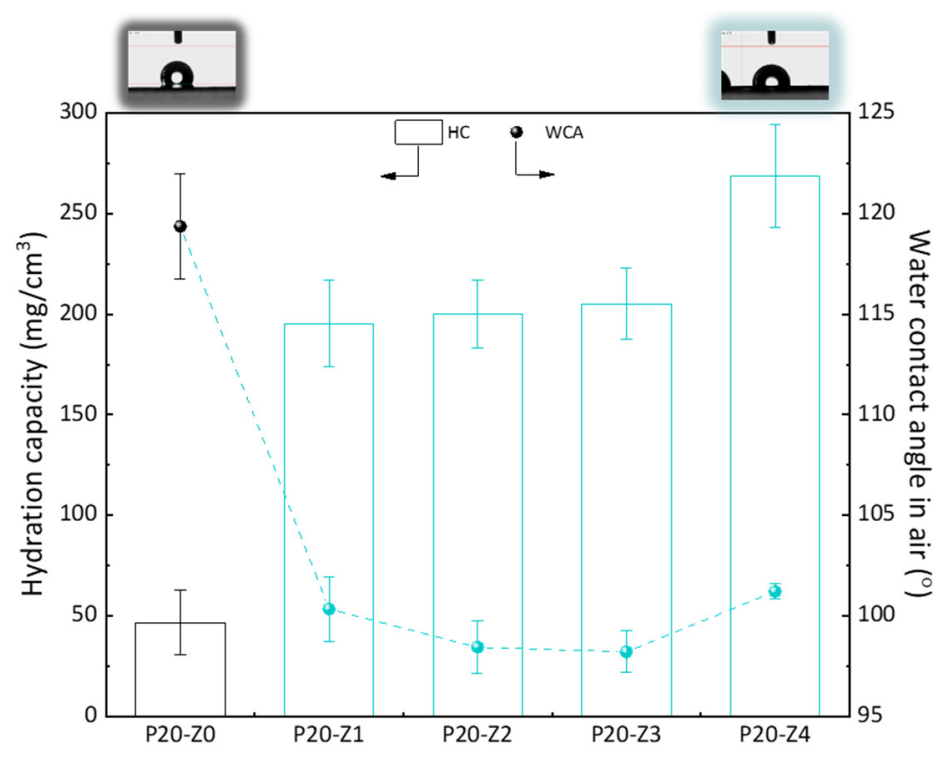

Figure 8. Hydrophilic properties of membranes.

\subsection{Effect of the Zwitterionic Copolymer on Resistance to Biofouling by Escherichia coli Bacteria}

Bacteria are commonly found in wastewater [46] and the presence of these pathogens may pose a threat to the environment and to people. Pathogenic Escherichia coli have been identified in sewage treatment plants [47]. Removal of these pathogens can be achieved by porous membranes, but biofouling of the membrane material by these microorganisms can quickly occur [48], resulting in a severe decrease in permeability. Ideally, a membrane surface should resist bacterial attachment to mitigate the effect of biofilm formation.

In this study, the effect of $\mathrm{zP}(4-r-4 \mathrm{VP})$ copolymer on the resistance of polysulfone membranes to bacterial attachment was tested after incubation of the membrane for $24 \mathrm{~h}$ with a solution of E. coli. As seen in Figure 9, the virgin membrane (P20-Z0) is covered by bacterial species. Biofouling of polysulfone membranes by E. coli is a well-known issue for these membranes that has been reported in the literature many times [26,49], and can be rationalized by the formation of hydrophobic-hydrophobic interactions between the substrate and the cells. The addition of zwitterionic copolymer to the initial casting solution results in an important decrease in bacterial attachment. Hence, our results show that bacterial attachment on the P20Z4 membrane fell to less than 15\% (compared to the virgin membrane), and the antibiofouling property of P20-Z4 was almost comparable to that of the sulfobetaine methacrylate (SBMA) hydrogel control, a common antifouling material [50-52]. The zwitterionic copolymer promotes water trapping and the formation of a hydration layer which is thought to protect the membrane from biofouling. The results of Figure 8 reveal a drastic increase in hydration capacity. Water trapped after prolonged immersion in some aqueous medium (as during bacterial attachment tests) protects the polymer matrix from biofouling by preventing hydrophobic interactions. Chen and coworkers [53] stressed the importance of hydration to successfully design surfaces resistant to proteins or bacteria. $\mathrm{Wu}$ and coworkers demonstrated that one unit of PSBMA zwitterionic material could tightly bound with eight molecules of water, which explains its excellent resistance to nonspecific protein adsorption and cell adhesion [54]. To the best of our knowledge, a similar investigation has not been carried out with the zwitterionic material at play in this study. However, it seems reasonable to state that the successful resistance of zP(S$r$-4VP)-modified membranes to bacterial attachment also lies in the material's ability to promote hydration. 


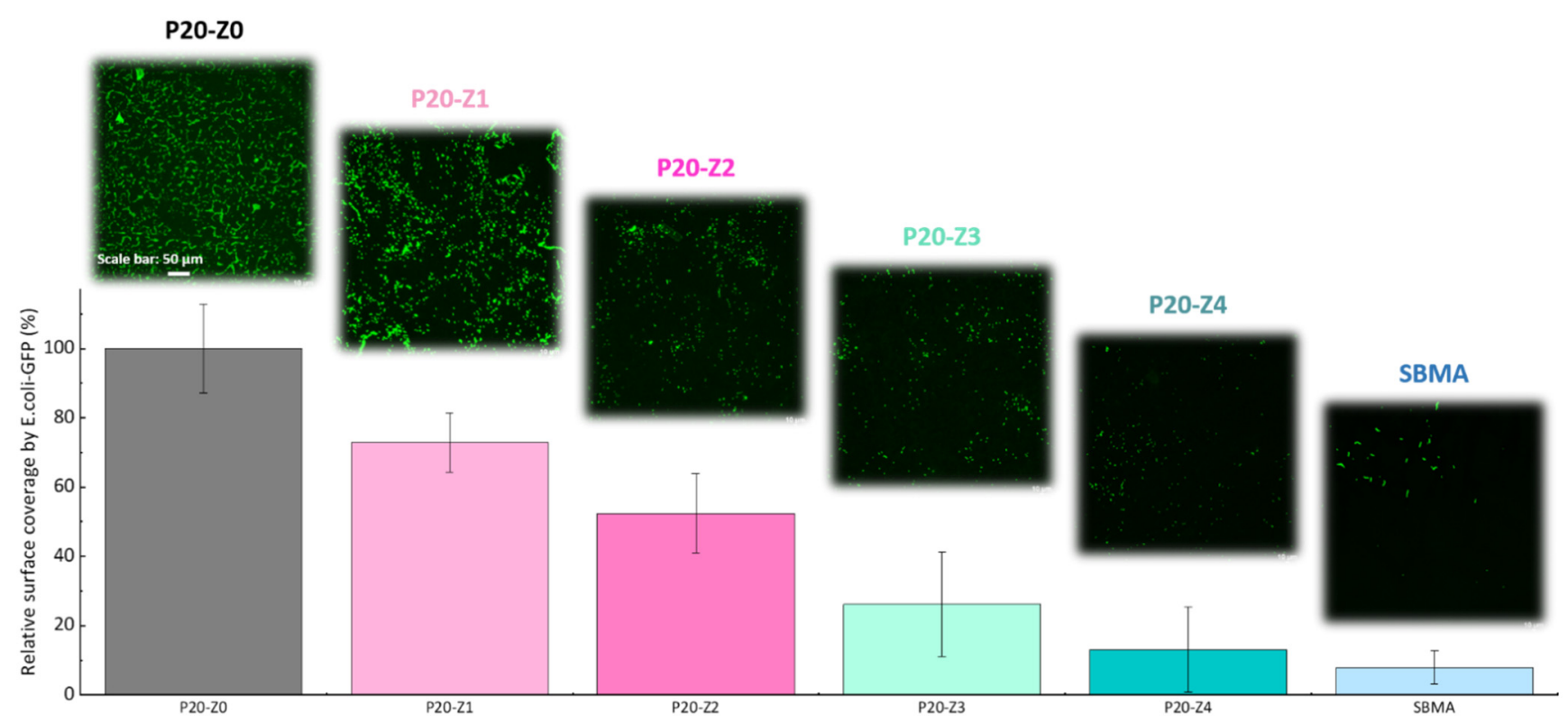

Figure 9. Effect of zwitterionic copolymer on the resistance of membranes to the attachment of Escherichia coli.

\subsection{Effect of the Zwitterionic Copolymer on Resistance to Biofouling by Whole Blood}

Polysulfone is commonly used as a base material for the design of hemodialysis membranes $[5,55,56]$. The study of Wenten and coworkers emphasized the need for a modification process in view of reducing blood protein adsorption that then leads to platelet adhesion and activation [56]. One highly efficient system is that presented by Ishihara et al. [57]: 2-methacryloyloxyethyl phosphorylcholine (MPC) polymer can drastically reduce the interactions of fibrinogen and platelets with a polysulfone membrane system, and hence improve its blood compatibility. The downside is related to the cost associated with the synthesis of MPC. Nevertheless, and based on these previous studies, the zwitterionization of polysulfone membranes by the in-situ modification method is a viable technique to improve the hemocompatibility of the membranes.

Here, we challenged the membranes against whole blood. As in the bacterial attachment test, membranes were incubated with whole blood and their surface observed by confocal microscope after fixing/staining the cells. The results provided in Figure 10 (1) demonstrate the efficiency of the copolymer in improving the blood compatibility of polysulfone membranes, (2) confirm that the blending method can be an efficient means to improve the blood compatibility of hydrophobic membranes and (3) show that despite not being entirely zwitterionic, unlike the SBMA control, P20-Z4 almost competes with purely zwitterionic hydrogel materials. These results could not have been obtained without a homogeneous and dense distribution of the copolymer on the surface of the membrane (Figure 8). The use of methanol as a first non-solvent bath likely facilitated diffusion of the copolymer chains leading to surface segregation (compared to the use of pure water which would lead to faster phase inversion and so faster solidification of the polymeric domains). Ultimately, it contributed to the excellent resistance to blood. 


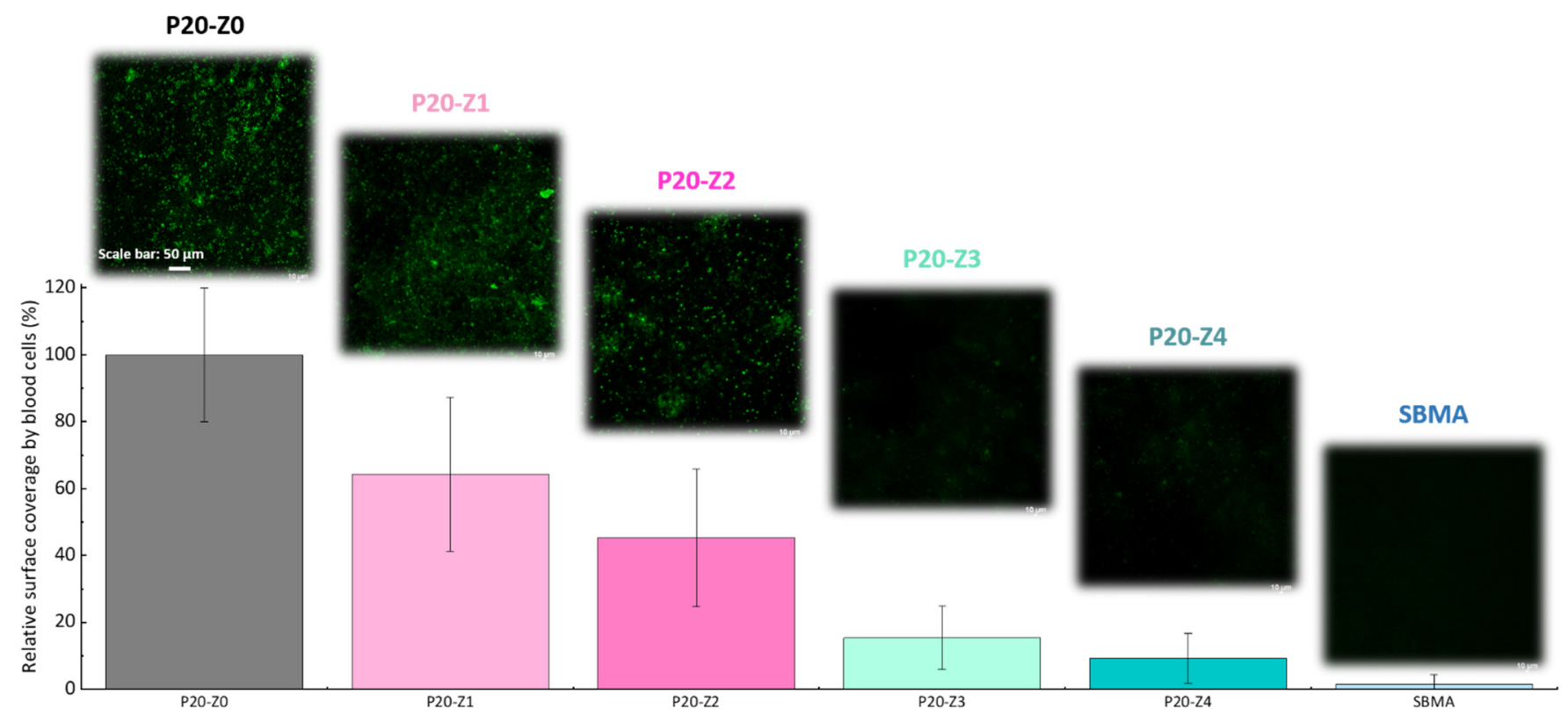

Figure 10. Effect of zwitterionic copolymer on the resistance of membranes to the attachment of cells from whole blood.

\subsection{Effect of the Zwitterionic Copolymer on Resistance to the Adsorption of Bovine Serum Albumin Protein}

The attachment of cells onto a membrane is often triggered by the earlier adsorption of proteins, smaller biofoulants, but the absence of cells does not indicate that the material surface is nonfouling. Biofouling by proteins occurs at a smaller scale than biofouling by cells, so it is harder to prevent. Pape et al. recently showed that films with non-celladhesive properties still displayed significant levels of protein adsorption [58]. Numerous techniques can be used to quantitatively or qualitatively assess protein adsorption on a material surface. Benavente et al. reported that mapping FT-IR was a powerful technique to evaluate the resistance to proteins of antifouling membranes [59], at relatively large scale $(\mathrm{mm})$. Here, we used a similar method to study the adsorption of BSA on the surface of P20-Z0 and P20-Z4 membranes. Analysis was carried out at $1650 \mathrm{~cm}^{-1}$, corresponding to the amide I functional group of the protein [60].

Results shown in Figure 11 highlight that the zwitterionic copolymer significantly reduced protein adsorption. While the map of the modified membrane (P20-Z4) was dominated by a light blue color after the incubation of the samples with the protein solution, that of the virgin membrane was mostly green. The light blue color indicates that the adsorption of BSA on the membrane surface is low according to the color-code. On the other hand, as the map turns green with orange and red spots, the adsorption of the protein is much more significant. A complementary quantitative test led to an adsorption level of $0.13 \mathrm{mg} / \mathrm{cm}^{2}\left( \pm 0.01 \mathrm{mg} / \mathrm{cm}^{2}, n=3\right)$ after immersion of the P20-Z0 membrane in a $1 \mathrm{~g} / \mathrm{L}$ BSA solution for $2 \mathrm{~h}$, and UV/Vis spectrophotometry measurements. This adsorption level could easily be reduced by $60 \%$ on P20-Z4 membrane, which indicates that the copolymer can also mitigate the biofouling propensity of small biomolecules. This is important as these biomolecules often trigger biofouling by larger biofoulants (cells). 


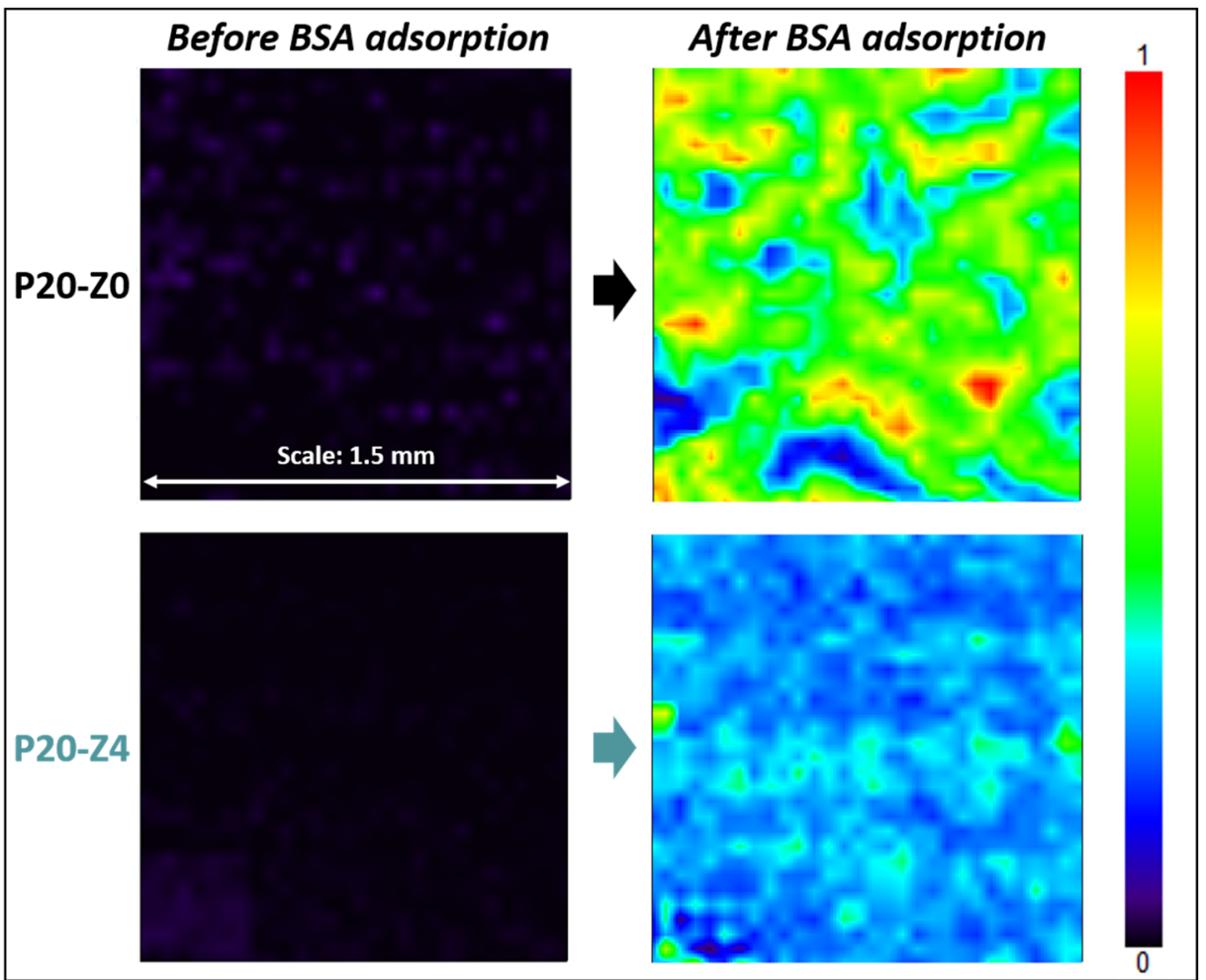

Figure 11. Effect of the additive on BSA adsorption. FT-IR maps at $1650 \mathrm{~cm}^{-1}$ of P20-Z0 and P20-Z4 before and after incubation with BSA solution.

\subsection{Effect of the Zwitterionic Copolymer on Resistance to Biofouling in Dynamic Conditions}

Membrane resistance to biofouling was also evaluated in dynamic conditions (as opposed to attachment tests that were static) by carrying out filtration tests with a protein solution. Bovine serum albumin is classically used to study membrane fouling during filtration, whether membranes fall in the microfiltration domain [61-64], or in the ultrafiltration range $[65,66]$. Here, filtration was carried out in dead-end mode. This configuration promotes the interactions of biofoulant materials with the membrane material by orienting the feed flux directly towards the membrane surface. Hence, short-term tests are sufficient to compare the antifouling performances of membranes. Tests were run with the pristine PSf membrane (P20-Z0) and the zwitterionic PSf membrane (P20-Z4), and results shown in Figure 12. The purpose of these tests was not to focus on rejection but to study the effect of the copolymer on the antifouling property during filtration. However, it is worth noting that the rejection after one cycle was $80.8 \pm 0.6 \%$ using P20-Z0, while it increased to $95.6 \pm 2.2 \%$ using P20-Z4 (measured from three independent tests).

Permeability results were normalized to be able to compare at first glance the performances of the membranes (Figure 12a). For the virgin membrane, the initial flux was about $17 \mathrm{LMH}$ at 3 bar, which is close to the findings of Madaeni and Rahimpour (18 LMH at 4 bar) [67]. This low permeability can readily be explained by the fact we did not use any pore-forming agent to prepare the virgin membrane, unlike in most reports [31-33]. For example Xu et al. used as much ethylene glycol monomer ( $16 \mathrm{wt} \%)$ as there was polysulfone to prepare the virgin membrane [33]. Here, it was decided to not use any pore-forming agent to be able to evaluate the actual effect of the copolymer (thus, the prime objective was not to reach high flux). The permeability of the modified membrane was found to be $35 \mathrm{LMH}$ at the same transmembrane pressure; that is, a twofold increase was obtained thanks to the zwitterionic copolymer. As seen earlier, the copolymer not only modified the surface and bulk structure (physical effect), but also changed the membrane surface/bulk chemistry. Enlarging the pores in the cross-section benefited water permeability. Altering the bulk chemistry by adding zwitterionic units also acted in favor of faster transport. A 
similar effect of amphiphilic copolymers blended with hydrophobic polysulfone has been reported [68].
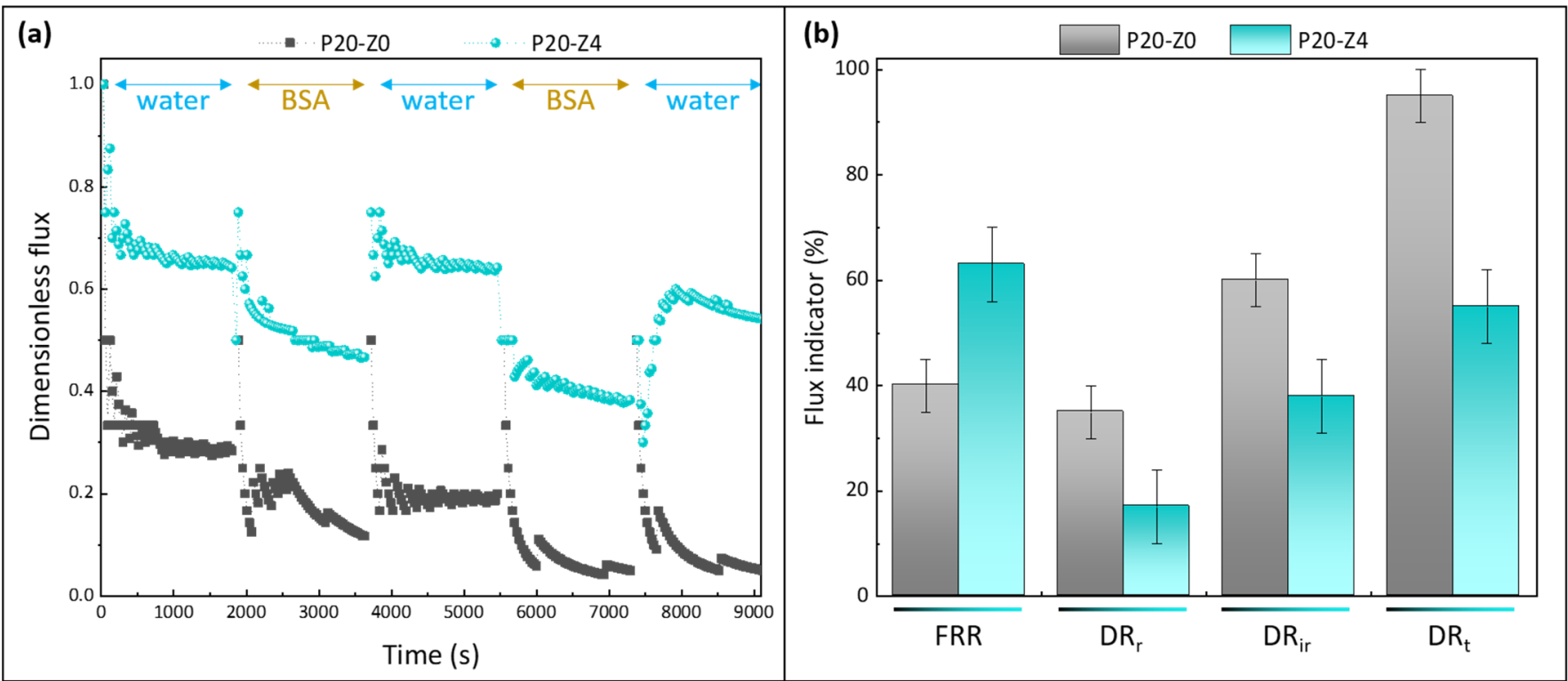

Figure 12. Effect of zwitterionic copolymer on the resistance of membranes to protein fouling during water/BSA cyclic filtration. (a): dimensionless flux; (b): flux indicator ratios (FRR: flux recovery ratio; $\mathrm{DR}_{\mathrm{r}}$ : reversible decline ratio; $\mathrm{DR}_{\mathrm{ir}}$ : irreversible decline ratio; $\mathrm{DR}_{\mathrm{t}}$ : total decline ratio). $n=3$ independent tests were carried out.

The copolymer clearly improved the flux recovery ratio of the membranes, averaging at about $63 \%( \pm 5 \%)$ at the end of the test using the modified membrane P20-Z4, while it was measured to be $40 \%$ using only the virgin membrane P20-Z0. Notably, the copolymer reduced irreversible fouling by BSA during the filtration procedure (from $60 \%$ for P20-Z0 to $38 \%$ for P20-Z4), which impacted the total flux decline. Thus, its effect was not only noticeable in static adsorption tests (Figure 11) but also during dynamic tests carried out in dead-end filtration, the filtration configuration in which fouling occurs the fastest. It is also important to note that the higher rejection measured with P20Z4, compared with $\mathrm{P} 20 \mathrm{Z0}$, is a consequence of smaller surface pore size and of the presence of antifouling units decorating the membrane surface which partially prevent protein adsorption and penetration in the bulk. Thus, despite a larger membrane pore size (10.4 nm vs. $6.3 \mathrm{~nm})$, the repelling effect of the copolymer permitted an increase in the protein rejection.

\subsection{Assessment of the Modified Membranes' Stability-Directions to Explore to Improve the Design}

Lastly, stability tests were conducted, consisting in immersing Z4 membranes for several weeks in a DI water bath. Subsequently, mapping FT-IR analyses were conducted. The purpose was to study the effect of the long-term immersion on the zwitterionic copolymer release from the membrane surface. The stability of membrane modification relies on hydrophobic-hydrophobic interactions in the case of in-situ modification (i.e., initial blending followed by phase-inversion). The hydrophobic forces are challenged by hydrophilic forces at play between the zwitterionic units of the copolymer and water from the aqueous environment in which membranes are immersed. These hydrophilic forces may result in the leaching of copolymer molecules, and so in a gradual loss of antifouling properties. Partial leaching of the zwitterionic copolymer from the polysulfone membrane could be detected from the results of Figure 13, as a change in color associated with a change in copolymer surface density. Nevertheless, it is undeniable that a large proportion of copolymer still remained trapped in the bulk of the membrane after 4 weeks, with a dominating orange-red color. Comparing these data with those presented earlier in Figure 6, the surface of the 
Z4 membrane immersed in DI water for several weeks still displayed a higher copolymer density than the surface of the $\mathrm{Z} 3$ membrane. Thus, the loss of material, though detectable, remains small and controllable.

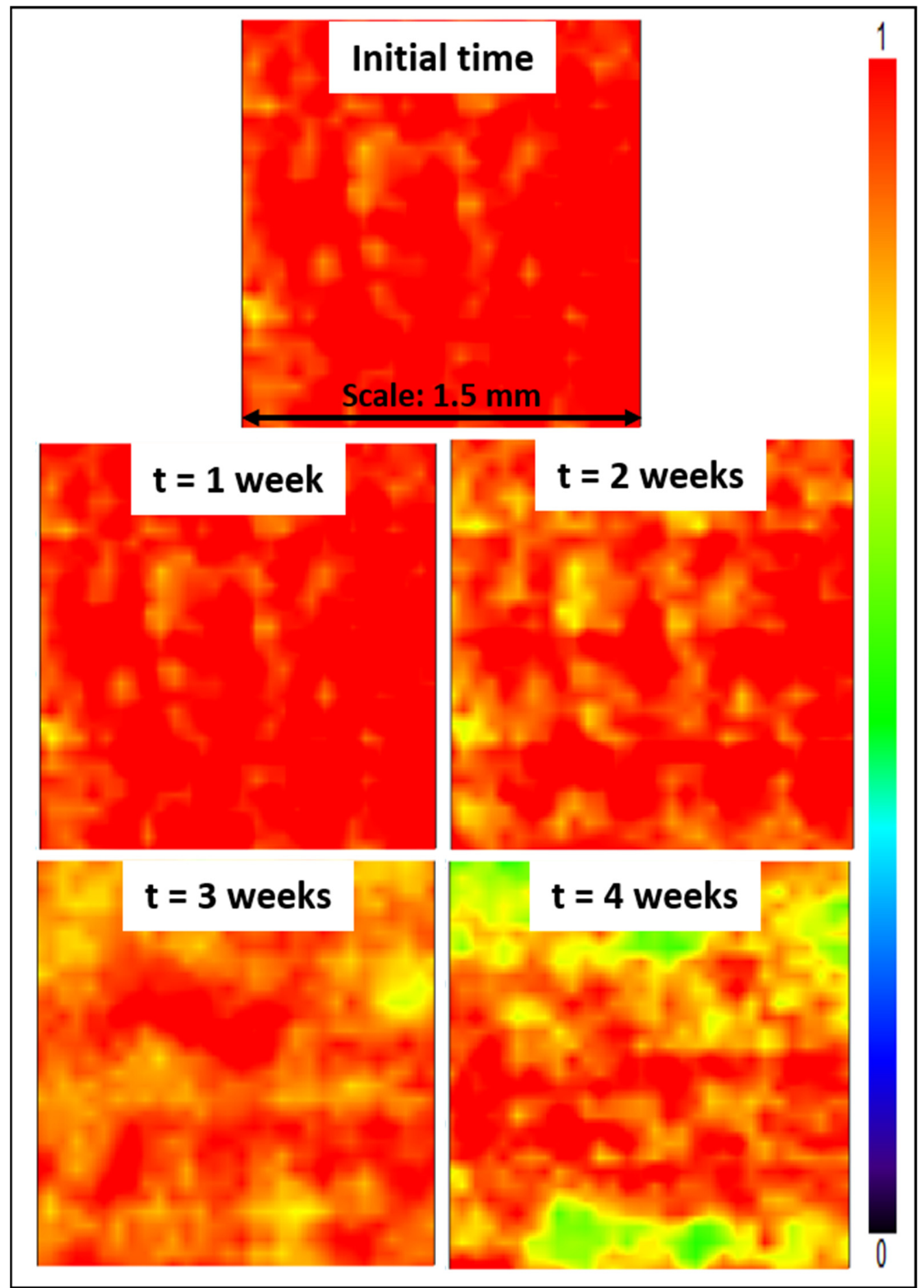

Figure 13. Mapping FT-IR images at $1727 \mathrm{~cm}^{-1}$ before and after immersing the membranes in DI water for 4 weeks.

The results gathered and evaluated in this study and from our previous studies [30] indicate that the zwitterionic poly(styrene-co-4-vinylpyrridine) copolymer exhibits good versatility in terms of being able to provide effective antifouling properties on PVDF-based membranes. However, efforts can still be made to fully materialize the efficiency of these 
antifouling membranes. On this note, several directions are now being investigated in our team to improve further the stability of the membranes. More details are provided as follows.

- Increasing the length of the hydrophobic segments, i.e., augmenting the relative proportion of styrene units, would be the most evident method as it would permit the strengthening of the stabilizing hydrophobic interactions (and in the meantime weaken the hydrophilic interactions).

- $\quad$ Reducing the zwitterionic degree of the 4VP units (from $78 \%$ as in this work to a lower value) may provide a good tradeoff between the reduction of destabilizing hydrophilic interactions and the preservation of antifouling properties.

- One could also consider changing the copolymer configuration. While we worked here with a random copolymer (it can be readily synthesized at relatively low costs), a block copolymer may lead to better stability and antifouling performances, although it would be more challenging to synthesize. In block configuration, all hydrophobic units would be entangled in the matrix, while most hydrophilic units would be found at the interface between the membrane and the surrounding environment. In other words, each unit would fulfill the function it was originally intended for. In random configuration, some isolated hydrophobic units surrounded by numerous hydrophilic units may not be entangled in the membrane and conversely, some hydrophilic units may be found trapped in the main polymer matrix.

\section{Conclusions}

Polysulfone membranes, modified with a zwitterionic copolymer obtained after a reaction of iodopropionic acid with poly(styrene-co-4-vinylpyrridine), were prepared by a dual-bath procedure. The goal was to evaluate the effect of the copolymer on membrane structure, arising properties, and its ability to mitigate fouling. After incubating the membranes with $E$. coli, biofouling was reduced by about $87 \%$, compared to the virgin membrane. Similarly, biofouling by whole blood was dramatically mitigated ( $90 \%$ reduction) as the adsorption level of blood cells on the P20-Z4 membrane (containing $4 \mathrm{wt} \%$ additive) was almost comparable to that measured using a control zwitterionic poly(sulfobetaine methacrylate) hydrogel. Biofouling tests involving BSA protein also demonstrated the ability of the membranes to mitigate biofouling at the nano scale over large surfaces (as seen from a mapping FT-IR analysis). A flux recovery ratio of $63 \%$ was obtained after cyclic BSA/water filtration tests with the modified membranes, while it was measured at $40 \%$ with the virgin membrane.

The present membranes are stable for several weeks and provide enhanced antibiofouling properties against a variety of biofoulants. Although the design can be improved to reach a better tradeoff between permeability, stability, and biofouling-resistance, it is believed that these membranes could be suitable for applications in the biomedical field where long-term stability is rarely needed (as membranes are often discarded after single use); high permeability is not the main focus, but biofouling-resistance is essential to prevent cell lysis.

Author Contributions: Conceptualization, A.V. and Y.C.; methodology, I.V.B.M. and A.V.; formal analysis, I.V.B.M., H.N.A. and M.M.G.L.; data curation, I.V.B.M., S.-H.T. and M.M.G.L.; writingoriginal draft preparation, A.V. and I.V.B.M.; writing-review and editing, A.V., Y.C. and R.R.A.; supervision, A.V., Y.C. and R.R.A.; project administration, A.V.; funding acquisition, A.V. All authors have read and agreed to the published version of the manuscript.

Funding: The authors express their sincere gratitude to the Ministry of Science and Technology for their financial support through the grants MOST 110-2221-E-033-003-MY3and 109-2628-E-033-001-MY3.

Institutional Review Board Statement: Not applicable.

Informed Consent Statement: Not applicable.

Data Availability Statement: Not applicable. 
Conflicts of Interest: The authors declare no conflict of interest.

\section{References}

1. Tan, X.; Rodrigue, D. A Review on Porous Polymeric Membrane Preparation. Part I: Production Techniques with Polysulfone and Poly (Vinylidene Fluoride). Polymers 2019, 11, 1160. [CrossRef] [PubMed]

2. Zodrow, K.; Brunet, L.; Mahendra, S.; Li, D.; Zhang, A.; Li, Q.; Alvarez, P.J. Polysulfone ultrafiltration membranes impregnated with silver nanoparticles show improved biofouling resistance and virus removal. Water Res. 2009, 43, 715-723. [CrossRef] [PubMed]

3. Barbari, T.; Datwani, S. Gas separation properties of polysulfone membranes treated with molecular bromine. J. Membr. Sci. 1995, 107, 263-266. [CrossRef]

4. Peng, Y.; Dong, Y.; Fan, H.; Chen, P.; Li, Z.; Jiang, Q. Preparation of polysulfone membranes via vapor-induced phase separation and simulation of direct-contact membrane distillation by measuring hydrophobic layer thickness. Desalination 2013, 316, 53-66. [CrossRef]

5. Koga, Y.; Fujieda, H.; Meguro, H.; Ueno, Y.; Aoki, T.; Miwa, K.; Kainoh, M. Biocompatibility of Polysulfone Hemodialysis Membranes and Its Mechanisms: Involvement of Fibrinogen and Its Integrin Receptors in Activation of Platelets and Neutrophils. Artif. Organs 2018, 42, E246-E258. [CrossRef]

6. Urducea, C.B.; Nechifor, A.C.; Dimulescu, I.A.; Oprea, O.; Nechifor, G.; Totu, E.E.; Isildak, I.; Albu, P.C.; Bungău, S.G. Control of Nanostructured Polysulfone Membrane Preparation by Phase Inversion Method. Nanomaterials 2020, 10, 2349. [CrossRef]

7. Han, M.-J. Thermodynamic and rheological variation in polysulfone solution by PVP and its effect in the preparation of phase inversion membrane. J. Membr. Sci. 2001, 202, 55-61. [CrossRef]

8. Kim, I.-C.; Lee, K.-H. Effect of various additives on pore size of polysulfone membrane by phase-inversion process. J. Appl. Polym. Sci. 2003, 89, 2562-2566. [CrossRef]

9. Park, H.C.; Kim, Y.P.; Kim, H.Y.; Kang, Y.S. Membrane formation by water vapor induced phase inversion. J. Membr. Sci. 1999, 156, 169-178. [CrossRef]

10. Pesek, S.; Koros, W. Aqueous quenched asymmetric polysulfone membranes prepared by dry/wet phase separation. J. Membr. Sci. 1993, 81, 71-88. [CrossRef]

11. Pinnau, I.; Koros, W.J. Structures and gas separation properties of asymmetric polysulfone membranes made by dry, wet, and dry/wet phase inversion. J. Appl. Polym. Sci. 1991, 43, 1491-1502. [CrossRef]

12. Hilal, N.; Ogunbiyi, O.O.; Miles, N.; Nigmatullin, R. Methods Employed for Control of Fouling in MF and UF Membranes: A Comprehensive Review. Sep. Sci. Technol. 2005, 40, 1957-2005. [CrossRef]

13. Chapman, R.G.; Ostuni, E.; Takayama, S.; Holmlin, R.E.; Yan, A.L.; Whitesides, G.M. Surveying for Surfaces that Resist the Adsorption of Proteins. J. Am. Chem. Soc. 2000, 122, 8303-8304. [CrossRef]

14. Zhang, R.; Liu, Y.; He, M.; Su, Y.; Zhao, X.; Elimelech, M.; Jiang, Z. Antifouling membranes for sustainable water purification: Strategies and mechanisms. Chem. Soc. Rev. 2016, 45, 5888-5924. [CrossRef] [PubMed]

15. Lowe, S.; O'Brien-Simpson, N.M.; Connal, L.A. Antibiofouling polymer interfaces: Poly(ethylene glycol) and other promising candidates. Polym. Chem. 2015, 6, 198-212. [CrossRef]

16. Leng, C.; Hung, H.-C.; Sun, S.; Wang, D.; Li, Y.; Jiang, S.; Chen, Z. Probing the Surface Hydration of Nonfouling Zwitterionic and PEG Materials in Contact with Proteins. ACS Appl. Mater. Interfaces 2015, 7, 16881-16888. [CrossRef]

17. Chiag, Y.-C.; Chang, Y.; Chen, W.-Y.; Ruaan, R.-C. Biofouling Resistance of Ultrafiltration Membranes Controlled by Surface Self-Assembled Coating with PEGylated Copolymers. Langmuir 2012, 28, 1399-1407. [CrossRef] [PubMed]

18. Liu, D.; Zhu, J.; Qiu, M.; He, C. Antifouling PVDF membrane grafted with zwitterionic poly(lysine methacrylamide) brushes. RSC Adv. 2016, 6, 61434-61442. [CrossRef]

19. Fang, L.-F.; Jeon, S.; Kakihana, Y.; Kakehi, J.-I.; Zhu, B.-K.; Matsuyama, H.; Zhao, S. Improved antifouling properties of polyvinyl chloride blend membranes by novel phosphate based-zwitterionic polymer additive. J. Membr. Sci. 2017, 528, 326-335. [CrossRef]

20. Hou, S.; Wang, X.; Dong, X.; Zheng, J.; Li, S. Renewable antibacterial and antifouling polysulfone membranes incorporating a PEO-grafted amphiphilic polymer and N-chloramine functional groups. J. Colloid Interface Sci. 2019, 554, 658-667. [CrossRef]

21. Zhong, D.; Wang, Z.; Zhou, J.; Wang, Y. Additive-free preparation of hemodialysis membranes from block copolymers of polysulfone and polyethylene glycol. J. Membr. Sci. 2021, 618, 118690. [CrossRef]

22. Yu, H.; Cao, Y.; Kang, G.; Liu, J.; Li, M.; Yuan, Q. Enhancing antifouling property of polysulfone ultrafiltration membrane by grafting zwitterionic copolymer via UV-initiated polymerization. J. Membr. Sci. 2009, 342, 6-13. [CrossRef]

23. Yue, W.-W.; Li, H.-J.; Xiang, T.; Qin, H.; Sun, S.-D.; Zhao, C.-S. Grafting of zwitterion from polysulfone membrane via surfaceinitiated ATRP with enhanced antifouling property and biocompatibility. J. Membr. Sci. 2013, 446, 79-91. [CrossRef]

24. Xiang, T.; Lu, T.; Xie, Y.; Zhao, W.-F.; Sun, S.-D.; Zhao, C.-S. Zwitterionic polymer functionalization of polysulfone membrane with improved antifouling property and blood compatibility by combination of ATRP and click chemistry. Acta Biomater. 2016, 40, 162-171. [CrossRef] [PubMed]

25. Shahkaramipour, N.; Jafari, A.; Tran, T.; Stafford, C.M.; Cheng, C.; Lin, H. Maximizing the grafting of zwitterions onto the surface of ultrafiltration membranes to improve antifouling properties. J. Membr. Sci. 2020, 601, 117909. [CrossRef] 
26. Ali, F.A.A.; Alam, J.; Shukla, A.K.; Alhoshan, M.; Ansari, M.A.; Al-Masry, W.A.; Rehman, S.; Alam, M. Evaluation of antibacterial and antifouling properties of silver-loaded GO polysulfone nanocomposite membrane against Escherichia coli, Staphylococcus aureus, and BSA protein. React. Funct. Polym. 2019, 140, 136-147. [CrossRef]

27. Khan, A.; Sherazi, T.A.; Khan, Y.; Li, S.; Naqvi, S.A.R.; Cui, Z. Fabrication and characterization of polysulfone/modified nanocarbon black composite antifouling ultrafiltration membranes. J. Membr. Sci. 2018, 554, 71-82. [CrossRef]

28. Li, X.; Janke, A.; Formanek, P.; Fery, A.; Stamm, M.; Tripathi, B.P. High permeation and antifouling polysulfone ultrafiltration membranes with in situ synthesized silica nanoparticles. Mater. Today Commun. 2020, 22, 100784. [CrossRef]

29. Nair, A.K.; Isloor, A.M.; Kumar, R.; Ismail, A.F. Antifouling and performance enhancement of polysulfone ultrafiltration membranes using CaCO3 nanoparticles. Desalination 2013, 322, 69-75. [CrossRef]

30. Dizon, G.V.; Venault, A. Direct in-situ modification of PVDF membranes with a zwitterionic copolymer to form bi-continuous and fouling resistant membranes. J. Membr. Sci. 2018, 550, 45-58. [CrossRef]

31. Chakrabarty, B.; Ghoshal, A.; Purkait, M.K. Preparation, characterization and performance studies of polysulfone membranes using PVP as an additive. J. Membr. Sci. 2008, 315, 36-47. [CrossRef]

32. Ma, Y.; Shi, F.; Ma, J.; Wu, M.; Zhang, J.; Gao, C. Effect of PEG additive on the morphology and performance of polysulfone ultrafiltration membranes. Desalination 2011, 272, 51-58. [CrossRef]

33. Xu, Z.; Liao, J.; Tang, H.; Li, N. Antifouling polysulfone ultrafiltration membranes with pendent sulfonamide groups. J. Membr. Sci. 2018, 548, 481-489. [CrossRef]

34. Tang, S.-H.; Venault, A.; Hsieh, C.; Dizon, G.V.; Lo, C.-T.; Chang, Y. A bio-inert and thermostable zwitterionic copolymer for the surface modification of PVDF membranes. J. Membr. Sci. 2020, 598, 117655. [CrossRef]

35. Osadchii, D.Y.; Olivos-Suarez, A.I.; Bavykina, A.V.; Gascon, J. Revisiting Nitrogen Species in Covalent Triazine Frameworks. Langmuir 2017, 33, 14278-14285. [CrossRef]

36. Hsiao, S.-W.; Venault, A.; Yang, H.-S.; Chang, Y. Bacterial resistance of self-assembled surfaces using PPOm-b-PSBMAn zwitterionic copolymer-Concomitant effects of surface topography and surface chemistry on attachment of live bacteria. Colloids Surfaces B: Biointerfaces 2014, 118, 254-260. [CrossRef]

37. Bokhorst, H.; Altena, F.; Smolders, C. Formation of asymmetric cellulose acetate membranes. Desalination 1981, 38, 349-360. [CrossRef]

38. Yu, L.; Yang, F.; Xiang, M. Phase separation in a PSf/DMF/water system: A proposed mechanism for macrovoid formation. RSC Adv. 2014, 4, 42391-42402. [CrossRef]

39. Hung, W.-L.; Wang, D.-M.; Lai, J.-Y.; Chou, S.-C. On the initiation of macrovoids in polymeric membranes-Effect of polymer chain entanglement. J. Membr. Sci. 2016, 505, 70-81. [CrossRef]

40. Loh, C.H.; Wang, R. Insight into the role of amphiphilic pluronic block copolymer as pore-forming additive in PVDF membrane formation. J. Membr. Sci. 2013, 446, 492-503. [CrossRef]

41. Venault, A.; Liu, Y.-H.; Wu, J.-R.; Yang, H.-S.; Chang, Y.; Lai, J.-Y.; Aimar, P. Low-biofouling membranes prepared by liquidinduced phase separation of the PVDF/polystyrene-b-poly (ethylene glycol) methacrylate blend. J. Membr. Sci. 2014, 450, 340-350. [CrossRef]

42. Tian, X.; Qiu, Y.-R. 2-methoxyethylacrylate modified polysulfone membrane and its blood compatibility. Arch. Biochem. Biophys. 2017, 631, 49-57. [CrossRef] [PubMed]

43. Tu, M.-M.; Xu, J.-J.; Qiu, Y.-R. Surface hemocompatible modification of polysulfone membrane via covalently grafting acrylic acid and sulfonated hydroxypropyl chitosan. RSC Adv. 2019, 9, 6254-6266. [CrossRef]

44. Ostuni, E.; Chapman, R.G.; Holmlin, R.E.; Takayama, A.S.; Whitesides, G.M. A Survey of Structure-Property Relationships of Surfaces that Resist the Adsorption of Protein. Langmuir 2001, 17, 5605-5620. [CrossRef]

45. Hester, J.F.; Banerjee, A.P.; Mayes, A.M. Preparation of Protein-Resistant Surfaces on Poly(vinylidene fluoride) Membranes via Surface Segregation. Macromol. 1999, 32, 1643-1650. [CrossRef]

46. Frigon, D.; Biswal, B.K.; Mazza, A.; Masson, L.; Gehr, R. Biological and Physicochemical Wastewater Treatment Processes Reduce the Prevalence of Virulent Escherichia coli. Appl. Environ. Microbiol. 2013, 79, 835-844. [CrossRef]

47. Anastasi, E.M.; Matthews, B.; Stratton, H.; Katouli, M. Pathogenic Escherichia coli Found in Sewage Treatment Plants and Environmental Waters. Appl. Environ. Microbiol. 2012, 78, 5536-5541. [CrossRef] [PubMed]

48. Nguyen, T.; Roddick, F.A.; Fan, L. Biofouling of Water Treatment Membranes: A Review of the Underlying Causes, Monitoring Techniques and Control Measures. Membr. 2012, 2, 804-840. [CrossRef]

49. Tang, L.; Huynh, K.A.; Fleming, M.L.; Larronde-Larretche, M.; Chen, K.L. Imparting antimicrobial and anti-adhesive properties to polysulfone membranes through modification with silver nanoparticles and polyelectrolyte multilayers. J. Colloid Interface Sci. 2015, 451, 125-133. [CrossRef]

50. Lee, S.Y.; Lee, Y.; Le Thi, P.; Oh, D.H.; Park, K.D. Sulfobetaine methacrylate hydrogel-coated anti-fouling surfaces for implantable biomedical devices. Biomater. Res. 2018, 22, 1-7. [CrossRef]

51. Shen, J.; Du, M.; Wu, Z.; Song, Y.; Zheng, Q. Strategy to construct polyzwitterionic hydrogel coating with antifouling, dragreducing and weak swelling performance. RSC Adv. 2019, 9, 2081-2091. [CrossRef]

52. Wu, J.; He, C.; He, H.; Cheng, C.; Zhu, J.; Xiao, Z.; Zhang, H.; Li, X.; Zheng, J.; Xiao, J. Importance of zwitterionic incorporation into polymethacrylate-based hydrogels for simultaneously improving optical transparency, oxygen permeability, and antifouling properties. J. Mater. Chem. B 2017, 5, 4595-4606. [CrossRef] [PubMed] 
53. Chen, S.; Li, L.; Zhao, C.; Zheng, J. Surface hydration: Principles and applications toward low-fouling/nonfouling biomaterials. Polymers 2010, 51, 5283-5293. [CrossRef]

54. Wu, J.; Lin, W.; Wang, Z.; Chen, S.; Chang, Y. Investigation of the Hydration of Nonfouling Material Poly(sulfobetaine methacrylate) by Low-Field Nuclear Magnetic Resonance. Langmuir 2012, 28, 7436-7441. [CrossRef] [PubMed]

55. Koga, Y.; Meguro, H.; Fujieda, H.; Ueno, Y.; Miwa, K.; Kainoh, M. A new hydrophilic polysulfone hemodialysis membrane can prevent platelet-neutrophil interactions and successive neutrophil activation. Int. J. Artif. Organs 2019, 42, 175-181. [CrossRef]

56. Wenten, I.; Aryanti, P.; Khoiruddin, K.; Hakim, A.; Himma, N. Advances in Polysulfone-Based Membranes for Hemodialysis. J. Membr. Sci. Res. 2016, 2, 78-89.

57. Ishihara, K.; Fukumoto, K.; Iwasaki, Y.; Nakabayashi, N. Modification of polysulfone with phospholipid polymer for improvement of the blood compatibility. Part 2. Protein adsorption and platelet adhesion. Biomaterials 1999, 20, 1553-1559. [CrossRef]

58. Pape, A.C.H.; Ippel, B.D.; Dankers, P.Y.W. Cell and Protein Fouling Properties of Polymeric Mixtures Containing Supramolecular Poly(ethylene glycol) Additives. Langmuir 2017, 33, 4076-4082. [CrossRef]

59. Benavente, L.; Coetsier, C.; Venault, A.; Chang, Y.; Causserand, C.; Bacchin, P.; Aimar, P. FTIR mapping as a simple and powerful approach to study membrane coating and fouling. J. Membr. Sci. 2016, 520, 477-489. [CrossRef]

60. Zhang, Y.; Ye, L.; Zhao, W.; Chen, L.; Zhang, M.; Yang, G.; Zhang, H. Antifouling mechanism of the additive-free $\beta$-PVDF membrane in water purification process: Relating the surface electron donor monopolarity to membrane-foulant interactions. $J$. Membr. Sci. 2020, 601, 117873. [CrossRef]

61. Le, T.-N.; Au-Duong, A.-N.; Lee, C.-K. Facile coating on microporous polypropylene membrane for antifouling microfiltration using comb-shaped poly(N-vinylpyrrolidone) with multivalent catechol. J. Membr. Sci. 2019, 574, 164-173. [CrossRef]

62. Astaraee, R.S.; Mohammadi, T.; Kasiri, N. Analysis of BSA, dextran and humic acid fouling during microfiltration, experimental and modeling. Food Bioprod. Process. 2015, 94, 331-341. [CrossRef]

63. Velasco, C.; Calvo, J.; Palacio, L.; Carmona, J.; Prádanos, P.; Hernández, A. Flux kinetics, limit and critical fluxes for low pressure dead-end microfiltration. The case of BSA filtration through a positively charged membrane. Chem. Eng. Sci. 2015, 129, 58-68. [CrossRef]

64. Zhou, Y.; Wang, Z.; Zhang, Q.; Xi, X.; Zhang, J.; Yang, W. Equilibrium and thermodynamic studies on adsorption of BSA using PVDF microfiltration membrane. Desalination 2012, 307, 61-67. [CrossRef]

65. Kanagaraj, P.; Neelakandan, S.; Nagendran, A.; Rana, D.; Matsuura, T.; Muthumeenal, A. Performance studies of PEI/SPEI blend ultra-filtration membranes via surface modification using cSMM additives. RSC Adv. 2015, 5, 27594-27602. [CrossRef]

66. Zin, G.; Penha, F.M.; Rezzadori, K.; Silva, F.L.; Guizoni, K.; Petrus, J.C.C.; Oliveira, J.V.; Di Luccio, M. Fouling control in ultrafiltration of bovine serum albumin and milk by the use of permanent magnetic field. J. Food Eng. 2016, 168, 154-159. [CrossRef]

67. Madaeni, S.S.; Rahimpour, A. Effect of type of solvent and non-solvents on morphology and performance of polysulfone and polyethersulfone ultrafiltration membranes for milk concentration. Polym. Adv. Technol. 2005, 16, 717-724. [CrossRef]

68. Sinha, M.K.; Purkait, M.K. Increase in hydrophilicity of polysulfone membrane using polyethylene glycol methyl ether. J. Membr. Sci. 2013, 437, 7-16. [CrossRef] 